\title{
Observed Storm Track Dynamics in Drake Passage
}

\author{
ANNIE FOPPERT \\ Centre for Southern Hemisphere Oceans Research, CSIRO Oceans and Atmosphere, Hobart, Tasmania, Australia
}

(Manuscript received 22 July 2018, in final form 17 January 2019)

\begin{abstract}
The dynamics of an oceanic storm track-where energy and enstrophy transfer between the mean flow and eddies-are investigated using observations from an eddy-rich region of the Antarctic Circumpolar Current downstream of the Shackleton Fracture Zone (SFZ) in Drake Passage. Four years of measurements by an array of current- and pressure-recording inverted echo sounders deployed between November 2007 and November 2011 are used to diagnose eddy-mean flow interactions and provide insight into physical mechanisms for these transfers. Averaged within the upper to mid-water column (400-1000-m depth) and over the 4-yr-record mean field, eddy potential energy $(\overline{\mathrm{EPE}})$ is highest in the western part of the storm track and maximum eddy kinetic energy ( $\overline{\mathrm{EKE}}$ ) occurs farther away from the SFZ, shifting the proportion of eddy energies from $\overline{\mathrm{EPE}} / \overline{\mathrm{EKE}}>2$ to about 1 along the storm track. There are enhanced mean $3 \mathrm{D}$ wave activity fluxes $\overline{\mathbf{W}}$ immediately downstream of SFZ with strong horizontal flux vectors emanating northeast from this region. Similar patterns across composites of Polar Front and Subantarctic Front meander intrusions suggest the dynamics are set more so by the presence of the SFZ than by the eddy's sign. A case study showing the evolution of a single eddy event, from 15 to 23 July 2010, highlights the storm-track dynamics in a series of snapshots. Consistently, explaining the eddy energetics pattern requires both horizontal and vertical components of $\mathbf{W}$, implying the importance of barotropic and baroclinic processes and instabilities in controlling storm-track dynamics in Drake Passage.
\end{abstract}

\section{Introduction}

The Southern Ocean and its dynamics are unique to the world's oceans, dominated by the zonally unbounded Antarctic Circumpolar Current (ACC) system. Quantifying the strongly inhomogeneous flow of the ACC, with along- and across-stream variability on many scales, is an observational challenge. Global ocean and climate models require parameterization of processes crucial for setting the stratification of the ACC, that is, eddy fluxes (of buoyancy, heat, momentum) and eddymean flow interactions, that in turn set the deep $(\geq 500 \mathrm{~m})$ isopycnal structure of the world's oceans (e.g., Toggweiler and Samuels 1995; Nikurashin and Vallis 2012). The zonally inhomogeneous nature of the eddy fluxes implies that the global influence of the ACC plays out in localized regions where the flow interacts with bathymetry (Rintoul 2018). Predicting and preparing for future climates rely on properly parameterizing these processes in climate models that require validation with direct observations.

Corresponding author: Annie Foppert, annie.foppert@csiro.au
The large-scale dynamics of the ACC are analogous to those of the midlatitude atmosphere, with storm tracks of increased eddy activity downstream of localized forcing (e.g., Williams et al. 2007; Bischoff and Thompson 2014; Chapman et al. 2015). While storm tracks do not have a consistent definition, they are associated with elevated likelihood of weather-generating storms in the atmosphere and of oceanic mesoscale eddies that are regions of increased eddy kinetic energy (EKE) and eddy heat flux (EHF). In the ACC, the forcing is orographic, that is, due to the mean flow's encounter with large bathymetric features, such as Macquarie Ridge, Pacific Antarctic Rise, Kerguelen Plateau, Southwest Indian Ridge, and Shackleton Fracture Zone (SFZ). The existence of oceanic storm tracks, where cross-frontal particle exchange (Thompson and Sallée 2012) and EHF (Foppert et al. 2017) are locally enhanced, complicates extrapolation of local observations to the rest of the ACC. Thus, application and interpretation of results of studies framed in a zonal-mean sense essentially neglect the existence and unique dynamics of these localized oceanic storm tracks.

The dynamics of a localized storm track, be it in the atmosphere or ocean, are fundamentally rooted in the 
interaction between the eddying and the mean flow (Williams et al. 2007). For example, studies of atmospheric storm tracks find they exist where baroclinic eddies initially grow by gaining energy from the mean flow and eddy-induced fluxes often cause the storm track to self-maintain (Hoskins and Valdes 1990) and eventually self-destruct downstream (Kaspi and Schneider 2011). The storm tracks are initiated in regions of high baroclinicity with elevated values of EKE persisting downstream of the initial perturbation. In the ACC, episodic baroclinic instability events have been observed as the main mechanism for EHF (Watts et al. 2016) and hotspots of EHF are often found in the lee of large bathymetric features (Foppert et al. 2017). Each baroclinic instability event is associated with a conversion from mean available potential energy (APE) to eddy potential energy (EPE) through a horizontal flux of heat/buoyancy across the mean upper baroclinic front by the eddying flow (Pedlosky 1987). The baroclinic production of EKE follows through a vertical eddy buoyancy flux. EKE can also be produced directly from the mean kinetic energy pool through a lateral eddy momentum flux during barotropic instability. While baroclinic and barotropic instabilities can be thought of as separate processes, a recent idealized ocean modeling study, with a standing meander forced by a submarine ridge, illustrates the presence of mixed barotropicbaroclinic instability in the ACC (Youngs et al. 2017).

Elevated EKE values observed in the atmosphere downstream of a localized forcing and region of highest baroclinicity have been explained, through numerical model simulations, by the idea of "downstream baroclinic development" (Orlanski and Sheldon 1993). In this process, an individual eddy depends on its neighboring upstream eddy for energy through geopotential flux convergence (Orlanski and Katzfey 1991; Orlanski and Sheldon 1993). The transfer of energy in this way allows the wave packet to move much faster than individual eddies propagate. Downstream baroclinic development has been observed in the atmosphere to be associated with eddy events that manifest as large storms, including a major winter blizzard (Danielson et al. 2006). The signature of downstream baroclinic development has been suggested in the ocean, where observations from Drake Passage show a spatial offset between EHF (i.e., high baroclinicity) and EKE (Foppert et al. 2017).

Transfers of energy between eddies and the mean flow in the ocean are typically investigated through eddy energy budgets based on time-mean eddy energy equations and are often presented as Lorenz diagrams (Lorenz 1955). When interpreted appropriately, this framework for eddy-mean flow interactions can provide useful insights into the dynamics of major ocean currents (e.g., Cronin 1996; Phillips and Rintoul 2000; Bishop et al. 2013). However, without knowledge of the physical process responsible for the different conversion terms, the interpretation of these eddy energy budgets is ambiguous (Plumb 1983). These ambiguities can be avoided by diagnosing a "wave activity flux." One major benefit of diagnosing eddy-mean flow interactions in a wave activity flux framework is that wave activity and its flux satisfy a conservation equation. Thus, in the absence of forcing or friction, the convergence of the flux is directly proportional to an increase in the wave activity. In other words, a convergence of wave activity flux is directly associated with eddy growth by gaining wave activity (energy and/or enstrophy) from the mean flow. Additionally, the vertical wave activity flux vector is associated with baroclinic processes and the horizontal flux vectors with barotropic processes (Takaya and Nakamura 2001). This makes it possible to diagnose the relative contributions of specific physical mechanisms to the dynamics of a storm track.

Eliassen and Palm (1961) first formulated a wave activity flux for a zonally averaged mean flow, with eddies defined as any deviation from the zonal mean. The Eliassen-Palm (EP) flux, as it has come to be known, provides insight into the relative importance of eddy heat and momentum fluxes, that is, of baroclinic and barotropic instabilities. While the EP flux, and the transformed Eulerian mean framework that often accompanies it, is a powerful tool for diagnosing eddymean flow interactions, the requisite zonally averaged background state makes it difficult to diagnose with observations and difficult to interpret in the zonally inhomogeneous ACC. Plumb (1985) formulated a wave activity flux in three dimensions for a propagating wave on a time-mean flow. Because of the zonal and temporal averaging in the formulation of the EP flux and Plumb's wave activity flux, respectively, neither has any phase dependence. Yet, by the same reasoning, the EP flux cannot represent eddy propagation and Plumb's flux cannot provide information about the time evolution of the eddy field. Wave activity flux can be further generalized to include the temporal dimension, such that no averaging is necessary to obtain phase dependence, so that the time evolution of stationary (Takaya and Nakamura 1997) and propagating (Takaya and Nakamura 2001) eddies are fully represented. Therefore, investigating the spatial and temporal evolution of interactions between waves propagating in three dimensions and a zonally asymmetric background mean flow is possible under specific assumptions (explicitly stated in section 2).

In this study, eddy-mean flow interactions in Drake Passage are diagnosed in a wave activity flux framework using in situ measurements from an array of current- and 
pressure-recording inverted echo sounders in the eddy rich Polar Frontal Zone downstream of a major bathymetric feature, the SFZ. The next section details the properties of an oceanic wave activity and its flux based on that of Takaya and Nakamura (2001). Section 3 describes the observational dataset and analysis thereof, as well as complementary satellite altimetry data. Section 4 presents the major results: 4-yr time-mean fields of wave activity, its flux, and eddy terms; composite-mean fields of Polar Front (PF) and Subantarctic Front (SAF) meander intrusions; and a case study highlighting the temporal evolution of a single eddy event. Section 5 discusses the dynamics and physical mechanisms at play in an oceanic storm track in Drake Passage and section 6 summarizes the study.

\section{A primer on wave activity flux}

For small amplitude, quasigeostrophic perturbations (i.e., eddies or waves) on a background mean geostrophic flow, a conservation equation can be formulated from a linear combination of total eddy energy $(\mathrm{EPE}+\mathrm{EKE})$ and eddy enstrophy $\varepsilon_{e}$ such that

$$
\frac{\partial M}{\partial t}+\nabla \cdot \mathbf{W}=D
$$

where $M$ is the wave activity density, $\mathbf{W}$ is the $3 \mathrm{D}$ wave activity flux vector, and $D$ is any diabatic or frictional forcing (Takaya and Nakamura 2001). The wave activity, $M=\rho(A+E) / 2$, where $A=\varepsilon_{e} /|\nabla \bar{q}|$ and $E=(\mathrm{EPE}+$ $\mathrm{EKE}) /\left(|\overline{\mathbf{u}}|-c_{p}\right)$ are proportional to eddy enstrophy and total eddy energy, respectively, is related to waveactivity pseudomomentum. Mean quasigeostrophic potential vorticity $\bar{q}$ and its anomaly, $q^{\prime}=\nabla^{2} \psi^{\prime}+\left(f^{2} \psi_{z}^{\prime} / N^{2}\right)_{z}$, have units of $\mathrm{s}^{-1}$; total eddy energy, EPE + EKE, has units of $\mathrm{m}^{2} \mathrm{~s}^{-2}$; and eddy enstrophy, $\varepsilon_{e}=0.5 q^{2}$, has units of $\mathrm{s}^{-2}$. Note that the phase speed of the eddies in the direction of $\overline{\mathbf{u}}, c_{p}$, must be known a priori to calculate this wave activity. As is conventional, $\psi$ is the total geostrophic streamfunction with its associated geostrophic velocity, $\mathbf{u}=(u, v)=\left(-\psi_{y}, \psi_{x}\right)$, and buoyancy, $b=f \psi_{z} ; f$ is a constant local Coriolis parameter; $N^{2}=\bar{b}_{z}$ is the mean squared buoyancy frequency; and $\rho=1035 \mathrm{~kg} \mathrm{~m}^{-3}$ is a nominal ocean density. Boldfaced variables denote vector quantities, subscripts $x, y$, and $z$ represent partial derivatives, overbars denote timemean quantities, and primes denote eddy (or perturbation) quantities. It should be noted that while Takaya and Nakamura (2001) define eddies as deviations from the 3D spatial mean, their formulation has also been applied to eddies defined as deviations from a temporal mean (e.g., Danielson et al. 2006; Nakamura et al. 2010; Wolf and Wirth 2017; Chapman et al. 2015).
Written this way, wave activity and its 3D flux have the important property of phase independence, that is, the quantities do not depend on location along the linear wave. Therefore, $M$ and $\mathbf{W}$ can be diagnosed locally and any spatial structure is dynamic rather than a consequence of the location along the wave. Takaya and Nakamura (2001) make three major assumptions to arrive at this formulation: 1) the steady basic flow is nearly unforced, 2) the waves/eddies are slowly changing in a Wentzel-Kramers-Brillouin (WKB) sense, and 3 ) the phase speed of the eddies in the direction of the background mean flow is nearly constant. These assumptions impose limitations on the diagnostic that may break down in the ACC, yet the following results and accompanying interpretations appear useful in understanding eddy-mean flow interactions in Drake Passage.

Equation (1) illuminates several important characteristics of wave activity, $M$, and its flux $\mathbf{W}$ in the absence of diabatic forcing and friction (i.e., for conservative waves where $D=0$ ). Namely, a wave activity flux convergence, $\nabla \cdot \mathbf{W}<0$, is directly associated with an increase in local wave activity and a flux divergence is associated with a decrease in $M$. For example, Takaya and Nakamura (2001) find $\mathbf{W}$ converging into a composite-mean of amplifying blocking atmospheric highs. The amplifying highs represent eddies growing at the expense of the mean flow through an increase in wave activity. Additionally, time averaging Eq. (1) reveals that the flux is nondivergent for steady, conservative waves and that a divergence or convergence of $\overline{\mathbf{W}}$ is directly related to nonconservative or nonlinear effects. For instance, Takaya and Nakamura (2001) show $\overline{\mathbf{W}}$ is divergent over a region of surface heat fluxes, that is, thermal forcing, acting as a source of wave activity in the atmosphere. Further, Danielson et al. (2006) are able to use this diagnostic to discuss nonlinearities in an atmospheric wave packet and its associated wave breaking. Finally, Takaya and Nakamura (2001) show that $\mathbf{W}$ is parallel to the group velocity of the Rossby wave packet. That is, $\mathbf{W}$ illustrates wave packet propagation and is, in general, perpendicular to the wave's phase lines and height anomaly contours.

The wave activity flux is the sum of a stationary and propagating component (Takaya and Nakamura 2001). Specifically, $\mathbf{W}=\mathbf{W}_{s}+M \mathbf{C}_{u}$, where the phase propagation of the eddies in the direction of the mean flow, $\mathbf{C}_{u}=c_{p} \cdot \overline{\mathbf{u}} /|\overline{\mathbf{u}}|$, has been assumed constant. Again, $c_{p}$ must be known prior to the calculation of the propagating component of the flux, a major restriction of this formulation. For a completely stationary eddy, where $c_{p}=0$, the propagating component of the flux, $M \mathbf{C}_{u}$, is 
exactly zero. The stationary wave activity flux for the ocean in depth coordinates can be written as

$$
\mathbf{W}_{s}=\frac{\rho}{2|\overline{\mathbf{u}}|}\left\{\begin{array}{c}
\bar{u}\left(\psi_{x}^{\prime 2}-\psi^{\prime} \psi_{x x}^{\prime}\right)+\bar{v}\left(\psi_{x}^{\prime} \psi_{y}^{\prime}-\psi^{\prime} \psi_{x y}^{\prime}\right) \\
\bar{u}\left(\psi_{x}^{\prime} \psi_{y}^{\prime}-\psi^{\prime} \psi_{x y}^{\prime}\right)+\bar{v}\left(\psi_{y}^{\prime 2}-\psi^{\prime} \psi_{y y}^{\prime}\right) \\
\frac{f^{2}}{N^{2}}\left[\bar{u}\left(\psi_{x}^{\prime} \psi_{z}^{\prime}-\psi^{\prime} \psi_{x z}^{\prime}\right)+\bar{v}\left(\psi_{y}^{\prime} \psi_{z}^{\prime}-\psi^{\prime} \psi_{y z}^{\prime}\right)\right]
\end{array}\right\},
$$

where Takaya and Nakamura (2001) explain that the terms of $\mathbf{W}_{s}$ represent two complementary dynamical processes.

The first process is associated with "backward transport" of mean westerly momentum due to horizontal eddy fluxes of momentum and buoyancy. (Recall that horizontal buoyancy flux is equivalent to a vertical momentum flux in a quasigeostrophic framework.) This eddy flux term $\mathbf{W}_{\text {eddy }}$ is made up of the terms in Eq. (2) with single derivatives of $\psi^{\prime}$. Specifically, the eddy fluxes can be written as

$$
\mathbf{W}_{\text {eddy }}=\frac{\rho}{2|\overline{\mathbf{u}}|}\left\{\begin{array}{c}
\bar{u}\left(\psi_{x}^{\prime 2}\right)+\bar{v}\left(\psi_{x}^{\prime} \psi_{y}^{\prime}\right) \\
\bar{u}\left(\psi_{x}^{\prime} \psi_{y}^{\prime}\right)+\bar{v}\left(\psi_{y}^{\prime 2}\right) \\
\frac{f^{2}}{N^{2}}\left[\bar{u}\left(\psi_{x}^{\prime} \psi_{z}^{\prime}\right)+\bar{v}\left(\psi_{y}^{\prime} \psi_{z}^{\prime}\right)\right]
\end{array}\right\}
$$

Of course, these terms are not identical to the terms in the eddy energy budgets, yet close inspection reveals they are indeed related. For example, $\psi_{x}^{\prime} \psi_{y}^{\prime}=-u^{\prime} v^{\prime}$ is an eddy momentum flux and $\psi_{x}^{\prime} \psi_{z}^{\prime}=v^{\prime} b^{\prime} / f$ is a scaled eddy buoyancy flux. Therefore, with $f$ negative in the Southern Ocean, a poleward eddy buoyancy flux and downward flux of westerly momentum is indicated by an upward vertical wave activity flux $\left(\mathbf{W}_{\text {eddy }}^{z}>0\right)$.

The second process is associated with work done by pressure fluctuations $\psi^{\prime}$ and can be approximately interpreted as a flux of geopotential anomaly by the sub or supergeostrophic gradient-wind flow (Takaya and Nakamura 2001). This ageostrophic flux term $\mathbf{W}_{\text {ageo }}$ is made up of the terms in Eq. (2) with double derivatives of $\psi^{\prime}$. Specifically, the ageostrophic fluxes can be written as

$$
\mathbf{W}_{\text {ageo }}=\frac{\rho}{2|\overline{\mathbf{u}}|}\left\{\begin{array}{c}
\bar{u}\left(-\psi^{\prime} \psi_{x x}^{\prime}\right)+\bar{v}\left(-\psi^{\prime} \psi_{x y}^{\prime}\right) \\
\bar{u}\left(-\psi^{\prime} \psi_{x y}^{\prime}\right)+\bar{v}\left(-\psi^{\prime} \psi_{y y}^{\prime}\right) \\
\frac{f^{2}}{N^{2}}\left[\bar{u}\left(-\psi^{\prime} \psi_{x z}^{\prime}\right)+\bar{v}\left(-\psi^{\prime} \psi_{y z}^{\prime}\right)\right]
\end{array}\right\}
$$

Takaya and Nakamura (2001) show for a zonally uniform mean westerly jet that $\psi_{x x}^{\prime} \approx f u_{a}, \psi_{y y}^{\prime} \approx f v_{a}$, and $\psi_{z z}^{\prime} \approx f w_{a}$ around trough and ridge lines, where the subscript $a$ indicates ageostrophic gradient wind velocities. Thus, for example, $\psi^{\prime} \psi_{x x}^{\prime} \approx \phi^{\prime} u_{a}$, where $\phi / f=\psi$ and $\phi$ is the geopotential anomaly.

For a linear plane wave, $\mathbf{W}_{\text {eddy }}$ dominates between the troughs and ridges where $\psi^{\prime}=0$ and $\mathbf{W}_{\text {ageo }}$ dominates at the troughs and ridges where the ageostrophic flow is strongest. $\mathbf{W}_{\text {eddy }}$ and $\mathbf{W}_{\text {ageo }}$ represent complementary dynamical processes and combine into a phaseindependent stationary wave activity flux. For more details on the physical interpretation of the wave activity flux terms, the reader is referred to section 4 of Takaya and Nakamura (2001).

\section{Data}

\section{a. Local dynamics array of CPIES}

A local dynamics array (LDA) of bottom-moored current- and pressure-recording inverted echo sounders (CPIES) was deployed from November 2007 through November 2011, as part of the cDrake project (www. cdrake.org; Chereskin et al. 2012). Figure 1 shows the LDA located in the interfrontal zone between the mean position of the PF and SAF, along with the other CPIES deployed during the experiment. The $40-\mathrm{km}$ spacing of the CPIES in the LDA allows for mapping of the mesoscale features in this eddy-rich region downstream of the Shackleton Fracture Zone (Firing et al. 2014). Each CPIES records hourly round-trip acoustic travel time $\tau$, bottom pressure $p_{b}$, bottom temperature, and near-bottom reference velocity measured outside the bottom boundary layer at $50 \mathrm{~m}$ above the seafloor. Fouryear time series of each quantity are 3-day low-pass filtered and subsequently resampled every $12 \mathrm{~h}$. The $\tau$ time series are further adjusted for the estimated inverted barometer effect, the latitudinal effect on gravity, the changes in pathlength as established by $p_{b}$, and the seasonal cycle (Firing et al. 2014). More details on the data collection and processing can be found in Tracey et al. (2013).

A gravest empirical mode analysis based on regional hydrography provides a profile of temperature and salinity, and thus geopotential anomaly $\phi$, for every value of $\tau$ measured by the CPIES (Chidichimo et al. 2014). The total geostrophic streamfunction is composed of a reference and a bottom-referenced baroclinic streamfunction: $\psi=\psi_{\text {ref }}+\psi_{\mathrm{bcb}}=p_{b} /\left(\rho_{b} f\right)+\phi / f$, where $\rho_{b}=1050 \mathrm{~kg} \mathrm{~m}^{-3}$ is a deep reference density and $p_{b}$ is the time-dependent bottom pressure. Within the LDA, Firing et al. (2014) objectively map total geostrophic streamfunction, its horizontal derivatives (i.e., total 

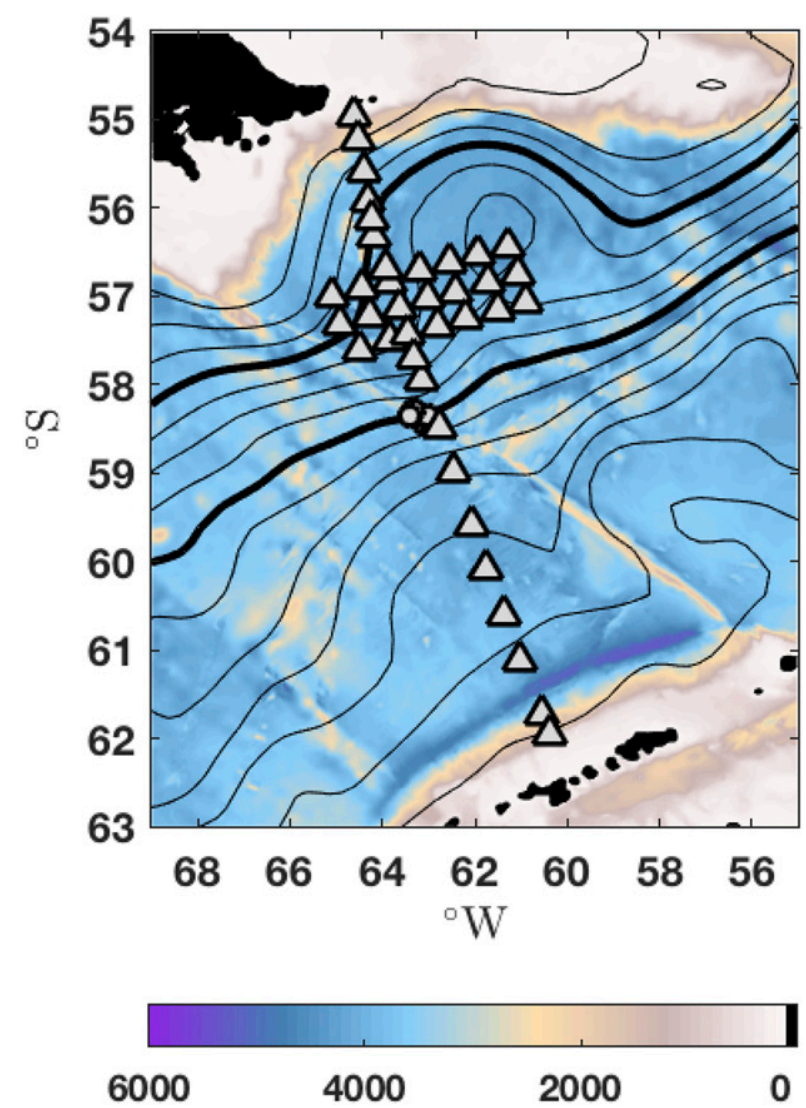

FIG. 1. Map of Drake Passage. Bathymetry (color shading; m) and mean SSH over the 4 years coincident with the cDrake experiment (black contours; interval $=0.1 \mathrm{~m}$ ). CPIES sites are shown as triangles and the five CPIES deployed for the last year of the experiment (not used in this study) are shown as circles. The LDA is the $3 \times 7$ array of CPIES located in the Polar Frontal Zone between the mean locations of the SAF and PF, with SSH contours representative of nominal SAF and PF shown in boldface.

geostrophic velocity), and its horizontal double derivatives (i.e., horizontal velocity shear). It can be noted that mapping errors on the geostrophic velocity and velocity shear are about $20 \%-25 \%$ of their mean values (Firing et al. 2014). Therefore, this work focuses on the patterns of $M$ and $\mathbf{W}$, as well as eddy energy and enstrophy, rather than closing the wave activity budget in Eq. (1) with a complete error analysis.

For this work, the phase speed of the eddies, and thus the propagating component of $\mathbf{W}$, is assumed to be zero. This assumption, while consistent with the assumption that the stationary flux is much larger than the propagating flux made by Chapman et al. (2015), may not be completely valid. However, there is no clear observed eddy phase speed in the ACC: propagation speeds of $\mathrm{SSH}$ anomalies in the Southern Ocean are small and can even change sign depending on latitude (Klocker et al. 2012); Radon transforms of altimetry measurements show mainly positive (eastward) zonal phase speeds within the ACC (Naveira Garabato et al. 2011); and another analysis of SSH anomalies find downstream propagation speeds of about $2 \mathrm{~cm} \mathrm{~s}^{-1}$ (Smith and Marshall 2009). Moreover, a plot of CPIES-derived $\psi^{\prime}$, where anomalies are defined as any deviation from the 90-day low-passed mean field, as a function of longitude and time within the LDA is complicated. There is no clear evidence of systematic wave/eddy propagation, with $\psi^{\prime}$ features translating both eastward and westward across the center of the LDA (along $57^{\circ} \mathrm{S}$; not shown). The lack of a consistent eddy propagation pattern leads to the assumption of zero phase speed, inherently neglecting the propagating wave activity flux and effectively reducing $\mathbf{W}$ to the wave activity flux of Takaya and Nakamura (1997). Therefore, the subscript from $\mathbf{W}_{s}$ is dropped and the stationary component of the wave activity flux is referred to as $\mathbf{W}$ hereafter. The value of $\mathbf{W}$ is calculated from the CPIES-derived mapped $\psi(x, y, z, t)$ fields, following Eq. (2).

Total eddy energy and eddy enstrophy are calculated directly from the CPIES measurements. EPE is calculated from the buoyancy field, where buoyancy has been calculated from each temperature and salinity profile. That is, $b=(-g / \rho)\left(\gamma-\gamma_{0}\right)$, where $g=9.8 \mathrm{~m} \mathrm{~s}^{-2}$ is a local gravitational acceleration, $\rho=1035 \mathrm{~kg} \mathrm{~m}^{-3}$ is the same standard ocean density as before, $\gamma_{0}=28.5 \mathrm{~kg} \mathrm{~m}^{-3}$ is a deep neutral density, and $\gamma$ is calculated with the neutral density package of Jackett and McDougall (1997). Specifically, EPE is written as

$$
\mathrm{EPE}=\frac{1}{2}\left(f \psi_{z}^{\prime} / N\right)^{2}=\frac{1}{2}\left(\frac{b^{\prime 2}}{N^{2}}\right)
$$

EKE is calculated from the total geostrophic velocity anomaly as

$$
\mathrm{EKE}=\frac{1}{2}\left(\psi_{x}^{\prime 2}+\psi_{y}^{\prime 2}\right)=\frac{1}{2}\left(u^{\prime 2}+v^{\prime 2}\right) .
$$

Finally, eddy enstrophy is calculated from the quasigeostrophic potential vorticity anomaly as

$$
\varepsilon_{e}=\frac{1}{2}\left[\nabla^{2} \psi^{\prime}+\left(f^{2} \psi_{z}^{\prime} / N^{2}\right)_{z}\right]^{2}=\frac{1}{2} q^{\prime 2} .
$$

As the LDA is located in the interfrontal zone where episodic intrusions of the PF and SAF occur, the "time mean" is defined to be a slowly varying mean, as has been employed in atmospheric studies (e.g., Nakamura et al. 2010; Wolf and Wirth 2017) and idealized modeling of oceanic storm tracks (Chapman et al. 2015). That is, anomalies (denoted by primes) are considered any deviation from the 90-day low-pass-filtered "mean" field 
such that, for example, $\bar{b}_{z}=N^{2}$ is the low-passed mean buoyancy frequency squared. A cutoff period of 90 days is consistent with the other observational studies that isolate the eddy band from the mean flow in the Southern Ocean (Phillips and Rintoul 2000; Nowlin et al. 1985). In this way, the mean field better represents mesoscale fronts during episodic intrusions rather than the interfrontal state of the 4-yr time mean. However, it can be noted that the patterns of $\mathbf{W}$ are not sensitive to the choice of background mean field; using various low-pass-filter lengths of 30, 90, and 180 days and using the 4-yr average as the mean field produce qualitatively consistent results (not shown). All of the following results are averaged between 400- and 1000-m depth, below the thermocline and away from surface interactions with the atmosphere, where diabatic forcing and friction are negligible. Consistent mean fields and consistent depth averaging used in all the analyses enables a harmonious interpretation between different diagnostics.

\section{b. Satellite altimetry}

The cDrake CPIES data are complemented with contemporaneous satellite altimetry to give a broader picture of the regional sea surface height ( $\mathrm{SSH}$ ) from November 2007 to November 2011. Total SSH is a combination of CNES-CLS13 mean dynamic topography and SSALTO/DUACS gridded daily mean sea level anomaly with a consistent reference period from 1993 to 2012. The mean dynamic topography was produced by CLS Space Oceanography Division and the sea level anomalies by the Copernicus Marine and Environment Monitoring Service; both are available online through AVISO at http://www.aviso.altimetry.fr. Both mapped products are provided on a $1 / 4^{\circ}$ horizontal resolution grid.

\section{Results}

\section{a. 4-yr-mean fields}

The 4-yr-mean stationary wave activity flux $\overline{\mathbf{W}}$ averaged between 400- and 1000-m depth is shown in Fig. 2. The largest values of $\overline{\mathbf{W}}$-both horizontal and vertical components-are found in the western LDA immediately downstream of the SFZ. These large fluxes are located in a mean SAF crest, where mean SSH contours meander poleward as the jet flows down the leeward side of the ridge (Figs. 1, 2). The vertical component of the flux $\overline{\mathbf{W}^{z}}$ is mostly positive (or very weakly negative) throughout the entire LDA, with peak values of about $0.4 \mathrm{~J} \mathrm{~m}^{-3}$ near $57.4^{\circ} \mathrm{S}, 64.8^{\circ} \mathrm{W}$ (Fig. 2). There is another local maximum in $\overline{\mathbf{W}}^{z}$ in the central LDA (near $57.5^{\circ} \mathrm{S}$, $63^{\circ} \mathrm{W}$ ) of about half the magnitude of the western peak. It can be noted that profiles of the vertical
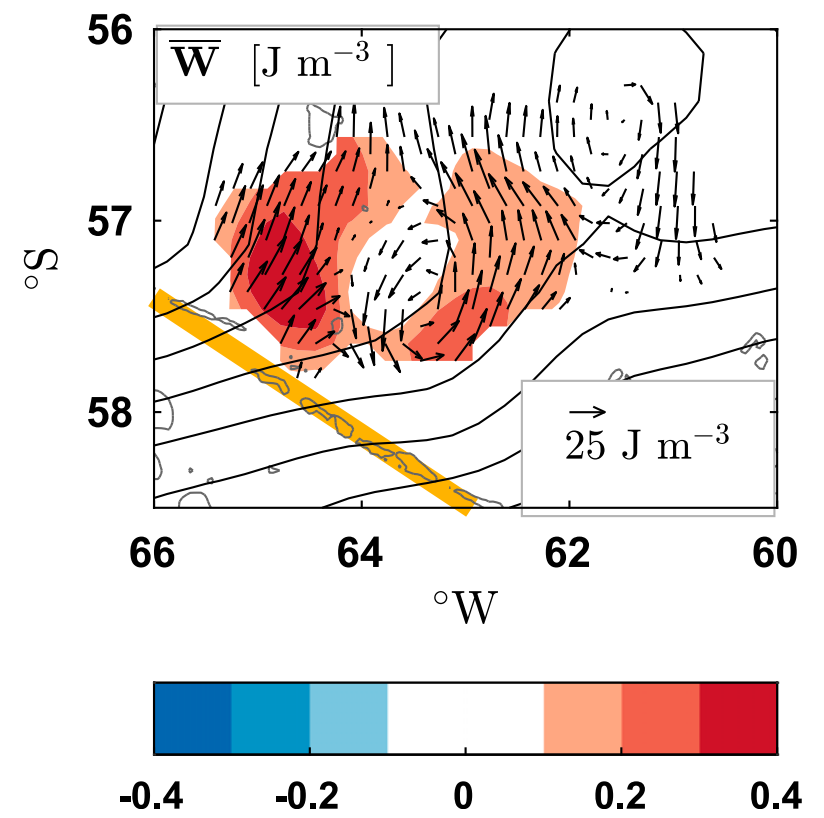

FIG. 2. The 4-yr-mean wave activity flux vectors $\overline{\mathbf{W}}\left(\mathrm{J} \mathrm{m}^{-3}\right)$ calculated relative to slowly varying, 90-day low-passed, mean quantities derived from the cDrake array of CPIES and averaged from 400- to 1000-m depth. The vertical flux $\overline{\mathbf{W}}^{z}$ is shown with colored shading, and the horizontal flux $\overline{\mathbf{W}^{H}}$ is shown with arrows (plotted at every other grid point). Mean satellite $\mathrm{SSH}$ from the same time period is contoured in black with a contour interval of $0.1 \mathrm{~m}$. The 3000-m bathymetry contour is shown in gray, and the thick orange line represents of the SFZ.

component of the mean flux $\overline{\mathbf{W}^{z}}$ are nearly constant with depth below about $200 \mathrm{~m}$ and profiles of the horizontal components of the mean flux $\overline{\mathbf{W}^{H}}$ tend to decay with depth (not shown).

In the western part of the LDA, averaged between 400- and 1000-m depth, $\overline{\mathbf{W}^{H}}$ vectors point generally northeast (Fig. 2). That is, mean wave activity is transmitted northeast and out of the LDA, roughly perpendicular away from the ridge. In the eastern and central LDA, $\overline{\mathbf{W}^{H}}$ vectors show some cyclonic and anticyclonic rotational features, respectively. The cyclonic $\overline{\mathbf{W}^{H}}$ in the eastern LDA appears to transport wave activity around the mean cold-core ring, seen as the closed SSH contour that sits in the northeast corner of the LDA. In the central LDA, the rotational aspects of the horizontal flux may be associated with the anticyclonic flow around the deepest part of the SAF crest. However, the interpretation of these rotational features remains questionable under the framework of linear dynamics. Therefore, the remaining analysis focuses on the main storm track in the western LDA in the immediate lee of the SFZ.

The 4-yr-mean wave activity, $\bar{M}$ again averaged between 400- and 1000-m depth, is concentrated in the 
northwest corner of the LDA (Fig. 3). The value of $\bar{M}$ is largely set by $\bar{E}$, mean total eddy energy scaled by $\left(\mathbf{u}-c_{p}\right)$, while $\bar{A}$, mean eddy enstrophy scaled by the mean quasigeostrophic potential vorticity horizontal gradient magnitude $|\nabla \bar{q}|$, is much weaker. Specifically, $\bar{A}$ is less than $10 \%$ of $\bar{E}$ throughout the main storm track in the western LDA, and $\bar{A}$ remains less than $20 \%$ of $\bar{E}$ throughout the entire LDA. It can be noted that introducing a positive $c_{p}$ would increase $\bar{E}$, making it a more dominant portion of $\bar{M}$. Mean eddy enstrophy $\bar{\varepsilon}_{e}$ and total eddy energy $(\overline{\mathrm{EPE}}+\overline{\mathrm{EKE}})$ are shown in Fig. 3 (bottom row). Both quantities are largest in the northwest corner of the LDA within the western storm track. Since $\bar{E}$ is the dominant factor in $\bar{M}$, the patterns of eddy potential and kinetic energies are considered in more detail.

Four-year-mean $\overline{\mathrm{EPE}}$ and $\overline{\mathrm{EKE}}$ are plotted in Fig. 4. The maximum value of $\overline{\operatorname{EPE}}\left(0.048 \mathrm{~m}^{2} \mathrm{~s}^{-2}\right)$ is almost double that of $\overline{\operatorname{EKE}}\left(0.028 \mathrm{~m}^{2} \mathrm{~s}^{-2}\right)$ and peak energies are not collocated in space. The $\overline{\mathrm{EPE}}$ field shows elevated values in the northwest corner of the LDA, slightly north of the main $\overline{\mathbf{W}}$ peak. The $\overline{\mathrm{EKE}}$ field is not as concentrated immediately in the lee of the SFZ, with relatively high values east of the $\overline{\mathbf{W}}$ peak and the local maximum farther from the bathymetric ridge (Fig. 4). There is a shift in the proportion of eddy energy over the LDA, with $\overline{\mathrm{EPE}}$ dominating in the northwest corner and $\overline{\mathrm{EKE}}$ dominating over the rest of the LDA, especially east of $63.5^{\circ} \mathrm{W}$.

Figure 5 presents the downstream evolution of $\overline{\mathbf{W}}$, $\overline{\mathrm{EPE}}$, and $\overline{\mathrm{EKE}}$ along the main storm track. The quantities are averaged in four sectors along the storm track, that is, four regions starting in the western LDA and subsequently heading in the direction of the mean $\mathbf{W}^{H}$ vectors (outlined in gray in Fig. 5, right panel). In each region along the storm track, all components of $\overline{\mathbf{W}}$ are positive. Designed this way, $\overline{\mathbf{W}^{z}}$ is strongest in the two upstream sectors of the storm track (labeled 1 and 2). The subsequent two downstream sectors (labeled 3 and 4) show decreasing $\overline{\mathbf{W}}^{z}$ values, abating to about half its original magnitude in the downstream-most sector in the north-central LDA.

$\overline{\text { EPE }}$ has a similar along-track pattern as $\overline{\mathbf{W}^{z}}$, with the highest values found in the upstream-most sector followed by decreasing values downstream (Fig. 5, left panels). In the upstream sectors of the storm track, the magnitude of $\mathbf{W}^{H}$ also decreases, reaching a local minimum in the middle of the track (sector 3 ), before it slightly increases farther downstream. In contrast, the weakest $\overline{\mathrm{EKE}}$ is found upstream (sector 1) and its largest values are found in the middle of the storm track. Thus, $\overline{\mathrm{EKE}}$ is strongest where $\overline{\mathbf{W}^{H}}$ is weakest, and $\overline{\mathbf{W}^{H}}$ is converging in the along-track direction as $\overline{\mathrm{EKE}}$ is growing (Fig. 5). Along the storm track, the partitioning of total eddy energy shifts from $\overline{\mathrm{EPE}}>2 \overline{\mathrm{EKE}}$ in the upstream region to $\overline{\mathrm{EPE}} \approx \overline{\mathrm{EKE}}$ farther downstream.

\section{b. Composite-mean fields}

As the LDA is located in a region between the mean position of the SAF and PF, where both jets actively meander into and out of the array, a composite mean of episodic eddy events helps to further elucidate the dynamics. To capture regional eddy events, the left column of Fig. 6 shows composites for time periods of elevated $\mathbf{W}^{z}\left(\geq 0.6 \mathrm{~J} \mathrm{~m}^{-3}\right)$ in the western LDA (defined as sectors 1 and 2 from Fig. 5). About $15 \%$ of the 4 years of data, 214.5 days, were considered "eddy events" and were used in the composites. This removes some of the variability in the full 4-yr-mean fields, more clearly illustrating the wave activity flux and eddy energetics patterns of the main oceanic storm track in Drake Passage.

The spatial patterns during eddy events in the western LDA in Figs. 6a, 6d, and $6 \mathrm{~g}$ are similar to those in Figs. 2 and 4, but the magnitudes are much larger. Composite-mean $\mathbf{W}^{z}$ is about 4 times as large, the magnitude of $\mathbf{W}^{H}$ about 3 times as large, EPE about twice as large, and EKE about 1.5 times as large as their respective 4-yr-mean fields. The elevated wave activity fluxes and eddy energies confirm that the eddy eventsevents of interest here-are well represented by the composite-mean fields. Additionally, Fig. 6a shows that the secondary peak in $\overline{\mathbf{W}^{z}}$ seen in the central LDA in Fig. 2 has been eliminated, suggesting that it is associated with separate eddy events specific to that region. Composite-mean $\mathbf{W}^{H}$ vectors again point northeast. Composite-mean EKE is again offset from the EPE and $\mathbf{W}$ maxima, with a convergence of $\mathbf{W}^{H}$ vectors at the EKE peak (Figs. 6g,j). Composite-mean $\mathbf{W}^{H}$ magnitude, $\mathbf{W}^{z}$, and EPE fields are well correlated in space $\left(R^{2}>0.7\right.$ for all three combinations at $95 \%$ confidence), whereas the composite-mean EKE fields is less correlated with the other three fields $\left(R^{2}<0.4\right.$ at $95 \%$ confidence in each case).

The composite-mean fields are further decomposed, approximately evenly, into PF trough intrusions and SAF crest intrusions into the western LDA (Fig. 6, center and right columns, respectively). As $f<0$ in Drake Passage, PF troughs are low pressure anomalies with $\psi^{\prime}>0$ and SAF crests are high-pressure anomalies with $\psi^{\prime}<0$. While the overall patterns are consistent between trough and crest events-elevated values of $\mathbf{W}$ and EPE in the western LDA with $\mathbf{W}^{H}$ vectors pointing northeast - there are some differences. In particular, the location of the EPE peak is farther north for PF trough events than SAF crest events (Figs. 6e,f). Similarly, 

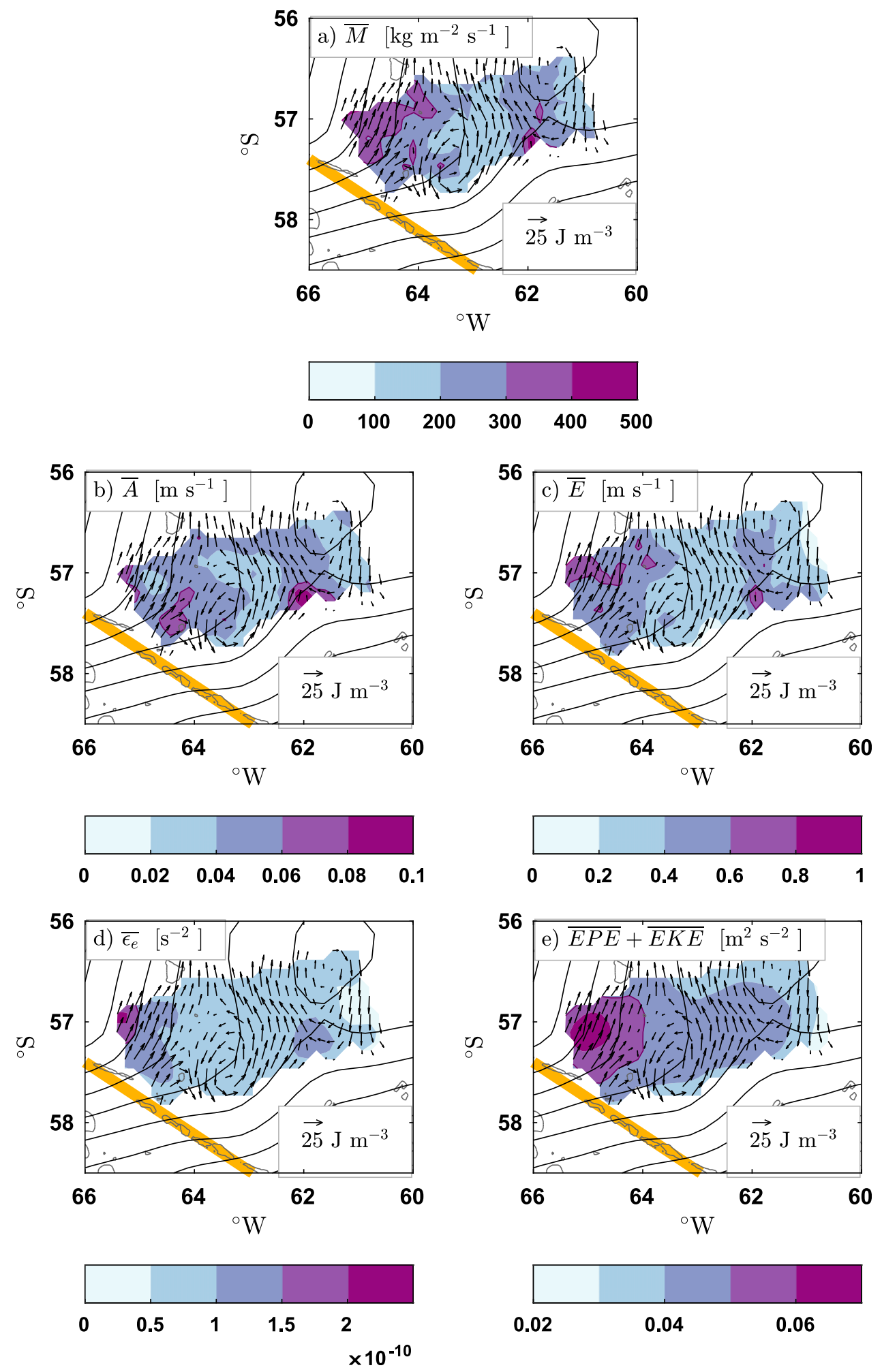

FIG. 3. The 4-yr-mean (a) wave activity $\bar{M}\left(\mathrm{~kg} \mathrm{~m}^{-2} \mathrm{~s}^{-1}\right)$; its partitioning between (b) scaled eddy enstrophy $\bar{A}\left(\mathrm{~m} \mathrm{~s}^{-1}\right)$ and (c) scaled eddy energy $\bar{E}\left(\mathrm{~m} \mathrm{~s}^{-1}\right)$; and (d) eddy enstrophy $\epsilon_{e}\left(\mathrm{~s}^{-2}\right)$, and (e) total eddy energy $\left(\mathrm{m}^{2} \mathrm{~s}^{-2}\right)$. All quantities are calculated relative to slowly varying, 90-day low-passed, mean quantities derived from the cDrake array of CPIES and averaged from 400- to 1000-m depth. As in Fig. 2, the 4-yr-mean $\overline{\mathbf{W}}^{H}$ vectors are plotted at every other grid point, mean satellite SSH from the same time period is contoured in black (contour interval of $0.1 \mathrm{~m}$ ), the $3000-\mathrm{m}$ bathymetry contour is shown in gray, and the thick orange line represents the SFZ. 

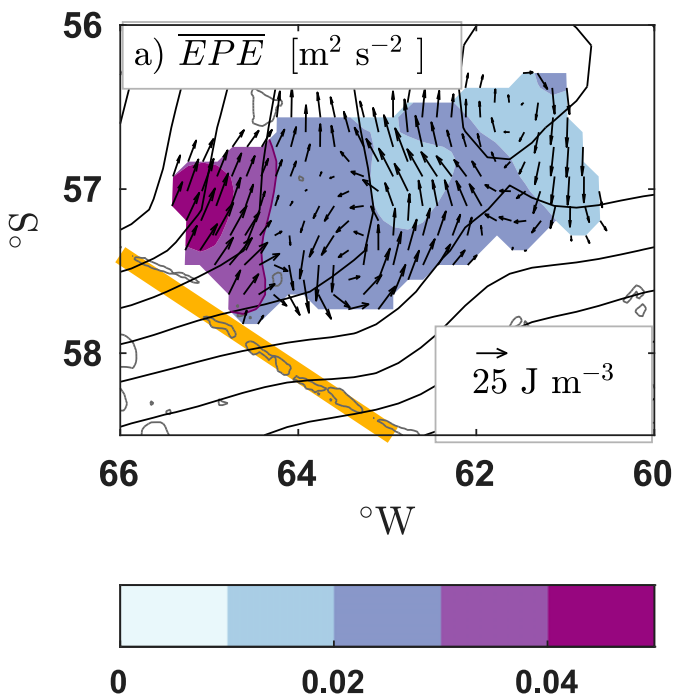
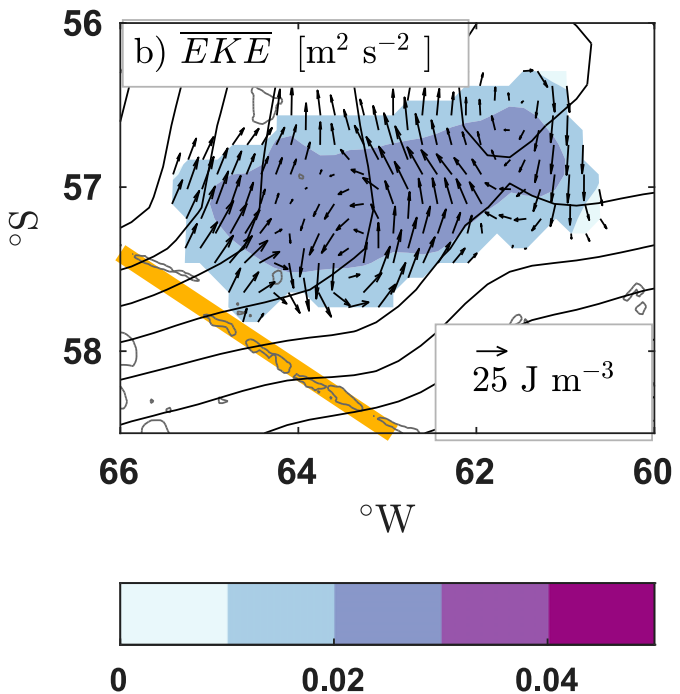

FIG. 4. The 4-yr-mean (a) EPE and (b) EKE $\left(\mathrm{m}^{2} \mathrm{~s}^{-2}\right)$ calculated relative to slowly varying, 90-day low-passed, mean quantities derived from the cDrake array of CPIES and averaged from 400- to 1000-m depth. As in Fig. 2, the 4-yr-mean $\overline{\mathbf{W}^{H}}$ vectors are plotted at every other grid point, mean satellite SSH from the same time period is contoured in black (contour interval of $0.1 \mathrm{~m}$ ), the 3000 -m bathymetry contour is shown in gray, and the thick orange line represents the SFZ

composite-mean eddy enstrophy fields show maximum values in the northwest corner of the LDA during PF events and the maximum is displaced to the south during SAF events (not shown). Additionally, Figs. 6e, 6f, 6h, and 6i show stronger EKE by about $0.01 \mathrm{~m}^{2} \mathrm{~s}^{-2}$ during $\mathrm{PF}$ intrusions than SAF intrusions.
Divergence of the horizontal wave activity flux $\nabla \cdot \mathbf{W}^{H}$ is plotted in Figs. 6j-1. Convergence of $\mathbf{W}^{H}$ is taken to be approximately equal to the full 3D convergence, as profiles of $\overline{\mathbf{W}^{z}}$ are roughly constant with depth below $200 \mathrm{~m}$ such that $\partial \mathbf{W}^{z} / \partial z \approx 0$ (not shown). Composite-mean EKE and flux divergence $\nabla \cdot \mathbf{W}^{H}$ fields show more spatial variability
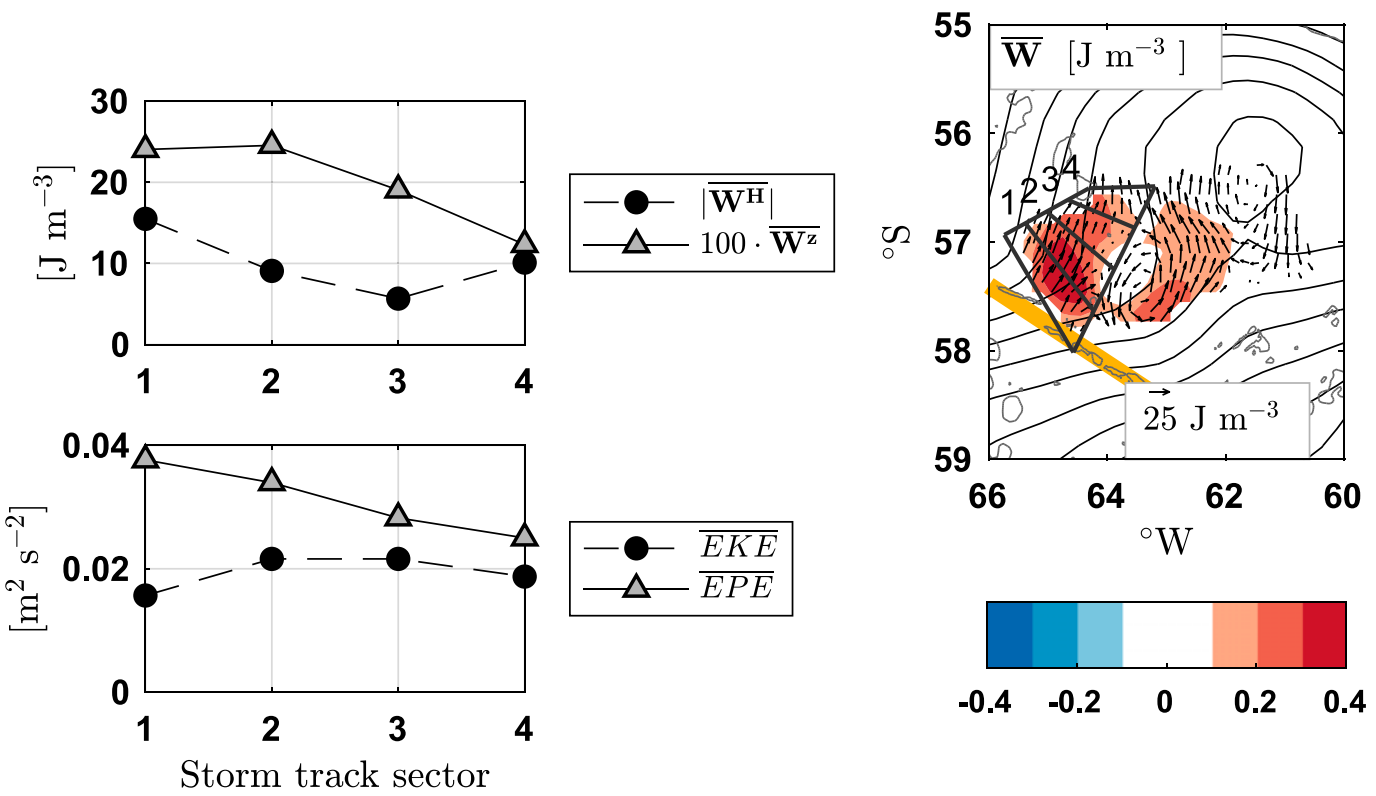

FIG. 5. (top left) Wave activity flux $\mathbf{W}\left(\mathrm{J} \mathrm{m}^{-3}\right)$ and (top right) eddy energies, EPE and EKE $\left(\mathrm{m}^{2} \mathrm{~s}^{-2}\right)$, in the western storm track. (right) Map showing four sectors where the values are averaged, with increasing sector number ( $x$ axis of left panels) increasing to the northeast, such that 1 represents the beginning of the storm track in the southwest sector and 4 represents the sector farthest downstream along the storm track observed in the LDA. The right panel is modified from Fig. 2, with added dark gray lines to distinguish the four sectors over which the values are averaged. 

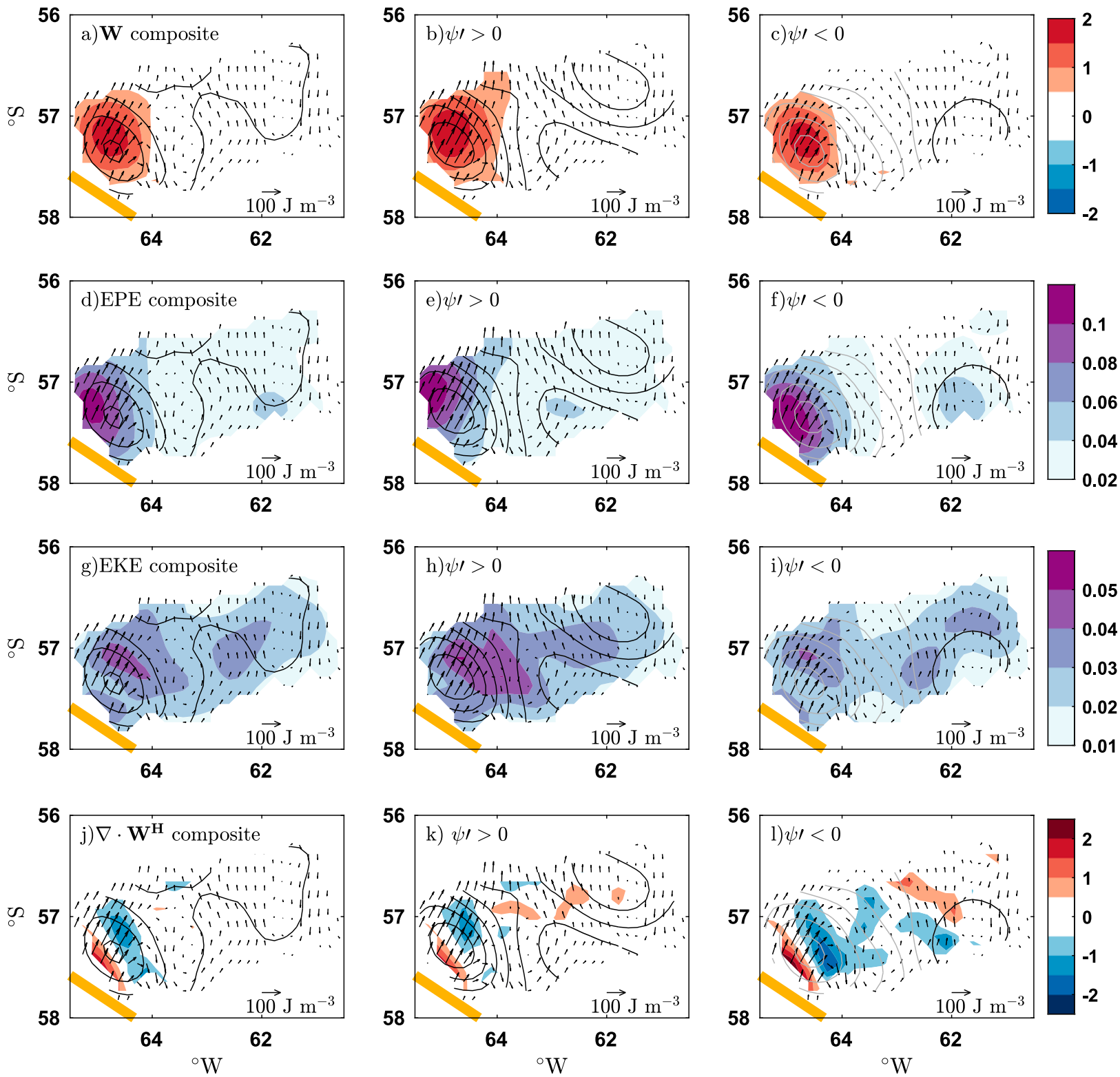

FIG. 6. Composite-mean values of (a)-(c) W $\left(\mathrm{J} \mathrm{m}^{-3}\right)$, (d)-(f) EPE $\left(\mathrm{m}^{2} \mathrm{~s}^{-2}\right)$, (g)-(i) EKE $\left(\mathrm{m}^{2} \mathrm{~s}^{-2}\right)$, and (j)-(l) $\nabla \cdot \mathbf{W}\left(\mathrm{J} \mathrm{m}^{-3} \mathrm{~km}{ }^{-1}\right)$. (left) The composite-mean fields are composed from the subset of 4-yr time series when there was elevated vertical wave activity flux (regionalmean $\mathbf{W}^{z}>0.6 \mathrm{~J} \mathrm{~m}^{-3}$ ) in the western LDA (sectors 1 and 2 in Fig. 5). (center),(right) Eddy events further decomposed into times when a PF trough $\left(\psi^{\prime}>0\right)$ and SAF crest $\left(\psi^{\prime}<0\right)$ intruded into the western LDA, respectively. Every panel has composite-mean $\mathbf{W}^{H}$ vectors plotted at every other point for orientation. Composite-mean $\psi^{\prime}$ fields $\left(\left|\psi^{\prime}\right|\right.$ in left column), contoured every $2000 \mathrm{~m}^{2} \mathrm{~s}^{-1}$ with zero and positive anomalies in black and negative anomalies in gray, represent the eddy field. As in previous figures, the thick orange line represents the SFZ.

between the two subsets of composites than EPE and $\mathbf{W}$ fields (Fig. 6, center and right columns). During PF trough events, the peak in EKE is offset slightly to the south of where the strongest $\mathbf{W}^{H}$ vectors point (Fig. 6h). During SAF crest events, $\mathbf{W}^{H}$ vectors point more directly from the EPE and $\mathbf{W}^{z}$ maxima toward the EKE maximum (Fig. 6, right column). The horizontal convergence of $\mathbf{W}^{H}$ is weaker and located farther north during PF trough events compared to SAF crest events (Figs. 6k,1). However, broadly speaking and consistent with the along-track view in Fig. 5, the peak in EKE is located where there is a convergence of $\mathbf{W}^{H}$.

Figure 7 shows the partitioning between eddy and ageostrophic components of the composite-mean $\mathbf{W}$ during eddy events, $\mathbf{W}_{\text {eddy }}$ and $\mathbf{W}_{\text {ageo }}$. The left column shows the total $\mathbf{W}$, such that Fig. 7a is identical to 

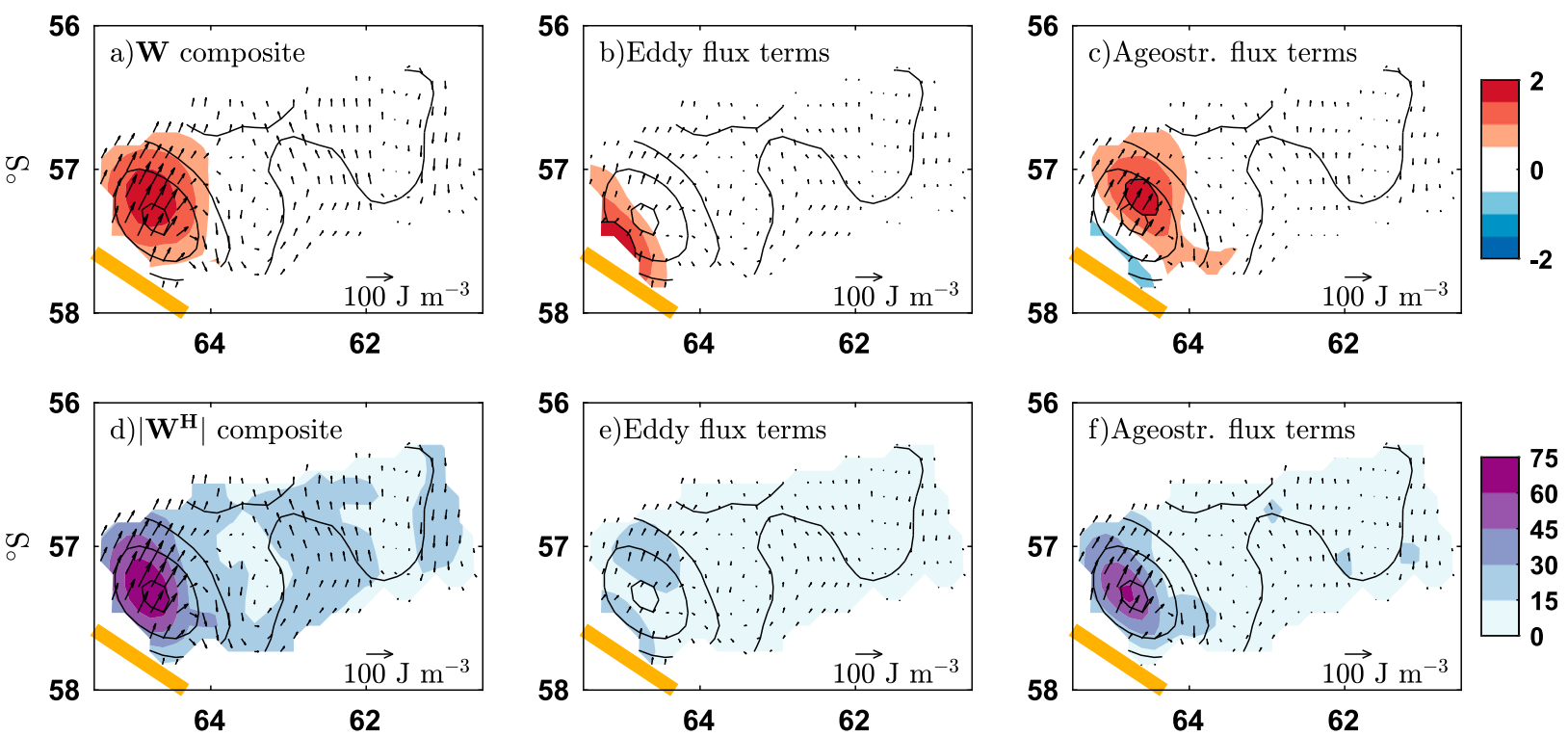

FIG. 7. Composite-mean values of the components of $\mathbf{W}\left(\mathrm{J} \mathrm{m}^{-3}\right)$ : (left) total, (center) eddy flux terms, and (right) ageostrophic flux terms. The colors represent the (top) vertical flux and (bottom) horizontal flux magnitude. The horizontal wave activity flux vectors of each component are plotted at every other grid point in both rows for orientation. The composite-mean fields are composed from the subset of 4-yr time series when there was elevated vertical wave activity flux (regional-mean $\mathbf{W}^{z}>0.6 \mathrm{~J} \mathrm{~m}^{-3}$ ) in the western LDA (sectors 1 and 2 in Fig. 5). Composite-mean $\left|\psi^{\prime}\right|$, contoured in black every $2000 \mathrm{~m}^{2} \mathrm{~s}^{-1}$, represents the eddy field, and the thick orange line represents the SFZ.

Fig. 6a, and Fig. 7d has color-contoured the magnitude of the horizontal flux $\left|\mathbf{W}^{H}\right|$. The vertical fluxes $\mathbf{W}_{\text {eddy }}^{z}$ and $\mathbf{W}_{\text {ageo }}^{z}$ are of approximately equal magnitude (Figs. $7 b, c)$, indicating a relatively equal distribution of influence between the two processes. Parameter $\mathbf{W}_{\text {eddy }}^{z}$, associated with horizontal eddy buoyancy flux, is spatially aligned with the location of the strongest observed divergent poleward EHF (Watts et al. 2016) and composite-mean EPE (Fig. 6d). Therefore, it is concluded that baroclinic eddies grow at the expense of the mean flow by converting mean APE to EPE in this region. There are two local maxima in $\left|\mathbf{W}_{\text {eddy }}^{H}\right|$ that surround the $\left|\mathbf{W}_{\text {ageo }}^{H}\right|$ maximum (Figs. 7e,f). Contrary to the vertical fluxes, where the strength of the eddy and ageostrophic flux terms are comparable, the maximum $\left|\boldsymbol{W}_{\text {ageo }}^{H}\right|$ is more than double the maximum $\left|\mathbf{W}_{\text {eddy }}^{H}\right|$. That is, the horizontal eddy momentum fluxes responsible for the backward transport of mean momentum are much less influential than the flux of geopotential anomaly by the sub or supergeostrophic gradient wind flow in the trough or crest, respectively.

\section{c. Case study: 15-23 July 2010}

Figure 8 illustrates the temporal evolution of the storm track during a single eddy event included in the composite-mean fields presented above. During this time, a PF trough intrudes into the western LDA and $\mathbf{W}$ and eddy energy locally increase for several days. The daily position of a nominal $\mathrm{PF}(\mathrm{SSH}=-0.3 \mathrm{~m})$ is shown in each panel as a reference, yet exact correspondence between satellite SSH and CPIES-derived $\psi$ fields is not expected. Recall that while SSH data are mapped at daily resolution, the sampling rate of the altimeter is 10 days, and that there has been no additional filtering performed on SSH. During this eddy event, shown in Fig. 8 from 15 to 23 July 2010 , a positive $\psi$ anomaly is present in the western part of the LDA, an adjacent negative $\psi$ anomaly is more centrally located, and a weaker positive $\psi$ anomaly exists in the eastern LDA. This train of $\psi$ anomalies, corresponding to a large meander-trough, crest, trough - in the SSH field, is the manifestation of an oceanic Rossby wave with a wavelength of about $200 \mathrm{~km}$.

This same event was documented in Fig. 7 of Watts et al. (2016) as an example of episodic divergent EHF event in the LDA, characterized by strong poleward EHF in the western part of the LDA and slightly weaker flux in the central LDA. In particular, those authors find baroclinic instability due to the joint intensification of upper and deep eddies (i.e., $\psi_{\text {ref }}$ and $\psi_{\text {bcb }}$ anomalies) associated with increasing divergent EHF between 16 and 19 July. EHF then decreases through 25 July while the anomalies weaken and move northeast out of the LDA. It can be noted that Watts et al. (2016) define anomalies as any deviation from the full 4-yr mean, while this analysis uses a 90-day low-passed mean field. Yet, Fig. 8 (top row) shows an intensification of $\mathbf{W}^{z}$ from 

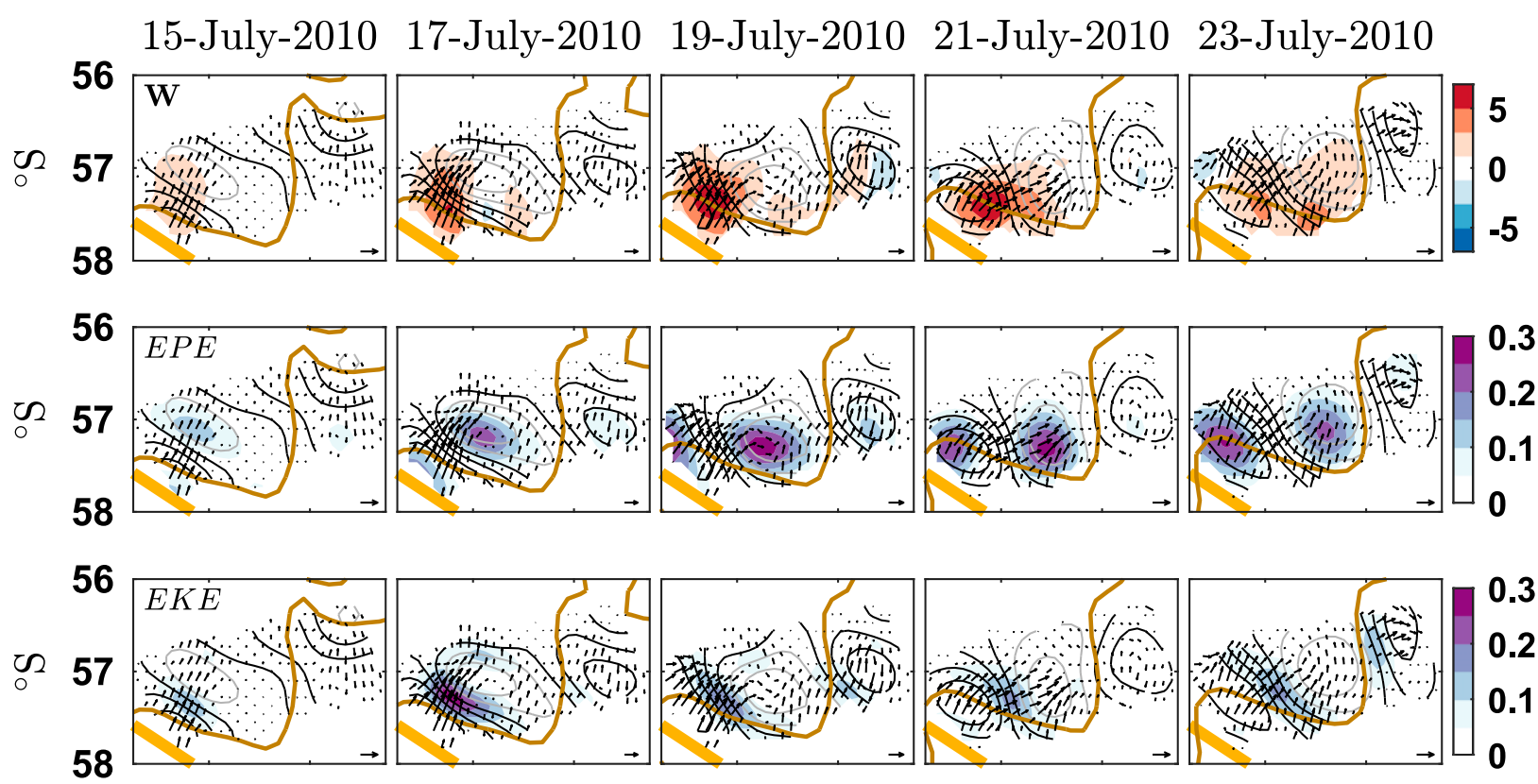

\section{3 \\ 0.2 \\ 0.1}

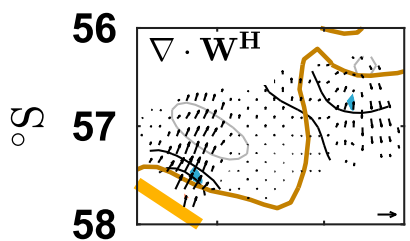

$64 \quad 62$ ${ }^{\circ} \mathrm{W}$

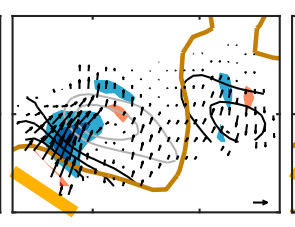

$64 \quad 62$ ${ }^{\circ} \mathrm{W}$

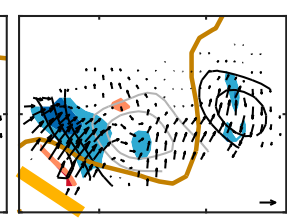

$64 \quad 62$ ${ }^{\circ} \mathrm{W}$

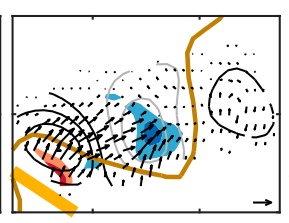

6462 ${ }^{\circ} \mathrm{W}$
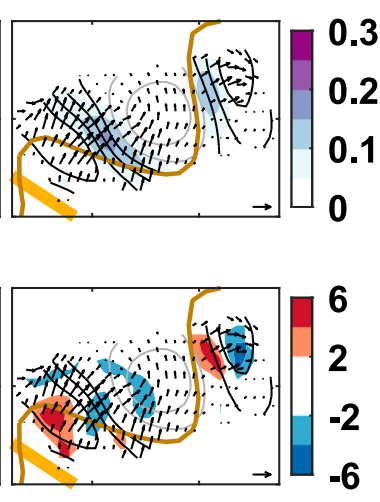

$64 \quad 62$ ${ }^{\circ} \mathrm{W}$

FIG. 8. Case study of the temporal evolution of an eddy event from (left) 15 to (right) 23 July 2010: (top) wave activity flux ( $\mathrm{J} \mathrm{m}^{-3}$ ) and (bottom) its horizontal divergence $\left(\mathrm{J} \mathrm{m}^{-3} \mathrm{~km}^{-1}\right)$, and (second row),(third row) eddy energies $\left(\mathrm{m}^{2} \mathrm{~s}^{-2}\right)$, EPE and EKE, respectively. The $\psi$ anomaly field (deviation from 90-day low-passed mean field) is contoured every $5000 \mathrm{~m}^{2} \mathrm{~s}^{-1}$, with $\psi^{\prime} \geq 0$ in black and $\psi^{\prime}<0$ in gray. A single SSH contour representative of the PF $(\mathrm{SSH}=-0.3 \mathrm{~m})$ is shown in brown. The horizontal wave activity flux vectors are plotted at every other grid point, and a reference vector with magnitude $200 \mathrm{~J} \mathrm{~m}^{-3}$ is plotted in the bottom-right corner of each panel. As in previous figures, the thick orange line represents the SFZ.

15 to 19 July and a subsequent decrease in $\mathbf{W}^{z}$ from 21 to $23 \mathrm{July}$, with the maximum value of $6.9 \mathrm{~J} \mathrm{~m}^{-3}$ realized on 20 July. That $\mathbf{W}^{z}$ evolves in time similarly to the divergent EHF documented by Watts et al. (2016) further validates the interpretation of $\mathbf{W}^{z}$ as an indicator of baroclinic instability.

In this case study, the vertical $\mathbf{W}^{z}$ peak tends to fall between western and central $\psi^{\prime}$ features (Fig. 8, top row), rather than in the center of the anomalies as in Fig 6 (top row). The strongest EKE is consistently found on the leading edge of the western $\psi$ anomaly and EPE peaks are found in the center of the western and central anomalies (Fig. 8). The largest value of EPE is found on 23 July in the western $\psi$ anomaly, while the largest value of EKE is found earlier in the event on 17 July.

As before, strong $\mathbf{W}^{H}$ vectors are collocated with the $\mathbf{W}^{z}$ peak and generally point across $\psi^{\prime}$ contours from the western anomaly to the central anomaly (Fig. 8, top row). The horizontal flux tends to be to the northeast throughout the whole event, but there is some slight turning of $\mathbf{W}^{H}$ eastward on 21 July. Comparison of the $\psi^{\prime}$ fields on 15 and 23 July shows that the large positive $\psi$ anomaly has translated in the same direction, from the southwest corner of the LDA toward the center of the CPIES array. On 17 and 19 July, there is a convergence of $\mathbf{W}^{H}$ that aligns well with the EKE peak (Fig. 8, bottom row). On 21 July, as the vectors turn more eastward, the horizontal convergence shifts into the center of the central $\psi$ anomaly, in a similar location to the EPE peak.

\section{Discussion}

\section{a. Dynamics of a storm track}

Wave activity flux $\mathbf{W}$ is a powerful diagnostic for examining interactions between eddies and the mean flow and is used here to investigate the dynamics of an 
oceanic storm track in Drake Passage. In the absence of diabatic forcing or friction, wave activity-a combination of total eddy energy and eddy enstrophy-is conserved [Eq. (1)]. In this framework, described in section 2, a convergence of $\mathbf{W}$ is directly linked to a local increase in wave activity $M$ and eddy growth at the expense of the mean flow. Additionally, $\mathbf{W}$ vectors illustrate wave packet propagation and illuminate the dynamics of storm tracks, regions of active jet meandering, eddy growth and instability. This study uses patterns of $\mathbf{W}$ to illuminate key dynamics that drive the eddy energetics in an oceanic storm track in Drake Passage, rather than close the local wave activity budget, as the uncertainties on $\mathbf{W}$ may be large and the assumptions made in the formulation may not be appropriate for evaluating an exact local budget (Takaya and Nakamura 2001). Yet, the patterns of $\mathbf{W}$ presented here illustrate the physical mechanisms governing this storm track's dynamics.

A striking feature of both the full 4-yr-mean and composite-mean fields (Figs. 2,6) is the consistency of the spatial patterns of the main oceanic storm track in Drake Passage. In all cases, an enhanced upward flux of wave activity is concentrated in the western LDA and large horizontal flux vectors emanate northeast from there. Here, it is shown that horizontal flux vectors in main storm track point to the northeast, that is, the Rossby wave packet propagates roughly perpendicularly away from the Shackleton Fracture Zone. The location of elevated $\mathbf{W}$-horizontal and vertical —is likely set by the SFZ, with the strongest fluxes where the fronts become unstable in the lee of the ridge. That the patterns remain similar between PF trough and SAF crest events (Fig. 6) suggests the sign of the eddy is a relatively inconsequential driver of storm track dynamics. Thus, it is inferred that the interaction between the fronts and the SFZ drive the location and dynamics of the oceanic storm track.

Stationary meanders associated with large-scale bathymetry in the ACC effectively prime the flow for baroclinic instability in the lee of large ridges. Under a certain configuration between the deep pressure field and the upper meander, that is, when the deep pressure field leads the upper geopotential anomaly field by a quarter wavelength, the anomalies of the upper and deep fields intensify together during baroclinic instability and cross-frontal EHF ensues (Pedlosky 1987). With CPIES observations in Drake Passage, Watts et al. (2016) illustrate that this upper-deep joint intensification and its associated divergent EHF is highest in the Polar Frontal Zone, where warm-core SAF and cold-core PF eddies actively grow, and is concentrated immediately downstream of the SFZ. However, observed wave activity fluxes presented in this work show the regional energetics in this oceanic storm track cannot be explained by baroclinic processes $\mathbf{W}^{z}$ alone (Figs. 5, 6, and 8).

To further complicate the picture, a jet's geostrophic streamlines are pinched together in the meander trough formed on the ridge, increasing the horizontal shear of the flow and the slope of the isopycnals. Therefore, the jet's barotropicity and baroclinicity, respectively, increase as it navigates the ridge. As the jet flow away from the stabilizing ridge, it may become susceptible to both mesoscale instabilities. A recent idealized modeling study finds mixed barotropic-baroclinic instability of a jet immediately in the lee of a simple ridge and changes in the instability properties downstream (Youngs et al. 2017). Here, CPIES observations in Drake Passage show both barotropic and baroclinic processes, represented respectively by elevated values of horizontal and vertical components $\mathbf{W}$, are important just in the lee of the SFZ where the SAF and PF meander (Figs. 2, 6). The coexistence of enhanced horizontal and vertical components of $\mathbf{W}$ suggests mixed barotropic-baroclinic instability occurs in this region.

Chapman et al. (2015) describe the time-mean dynamics of an oceanic storm in two regimes: baroclinic growth followed by downstream development. In their idealized model, vertical $\mathbf{W}$ dominates in the baroclinic growth regime and horizontal $\mathbf{W}$ dominates in the downstream development regime, with the horizontal fluxes transporting EKE away from the initial perturbation. Chapman et al. (2015) find the split between the growth regime and development regime occurs after at least one full wavelength of the standing Rossby wave and more than one local $\mathbf{W}^{z}$ maximum within the growth regime. However, the observations presented here show enhanced values of vertical and horizontal $\mathbf{W}$ collocated in space and time (Figs. 5, 8). The time-mean and composite-mean fluxes are highest within the first halfwavelength of the meander immediately in the lee of the SFZ (Figs. 2, 6). The presence of mixed barotropicbaroclinic instability in the first half-wavelength of the meander inferred here is supported by the geometric framework for eddy-mean flow interactions in the idealized modeling work of Youngs et al. (2017).

Orlanski and Sheldon (1995) describe three stages of downstream baroclinic development in the atmosphere. At first, energy from a preexisting mature eddy is carried downstream (through geopotential fluxes by the ageostrophic flow) to supply the growth of an adjacent eddy. As the initial eddy decays and this downstream eddy matures, energy is carried farther downstream to supply a third eddy. As the second begins to decay, the third eddy matures, and so on until the energy eventually dissipates 
downstream of the initial perturbation. Unlike the atmosphere or many modeling studies with a single idealized ridge in a reentrant channel (e.g., Chapman et al. 2015; Bischoff and Thompson 2014; Youngs et al. 2017), the ACC is often punctuated by bathymetry. That is, soon after its interaction with the SFZ, the PF must navigate the Scotia Arc and the SAF turns sharply northward along the South American continental slope. Upstream of the SFZ, the ACC encounters the Phoenix Ridge near $66^{\circ} \mathrm{W}$. Thus, the bathymetric complexity of the real ocean may interrupt the downstream development process seen in the atmosphere and idealized ocean models.

Figure 2 shows a secondary region of elevated $\overline{\mathbf{W}}$ located more centrally in the LDA near $63^{\circ} \mathrm{W}$. As in the western storm track, $\overline{\mathbf{W}}^{H}$ vectors emanate from a region of elevated $\overline{\mathbf{W}^{z}}$ to a region of elevated $\overline{\mathrm{EKE}}$ (Fig. $4 \mathrm{~b}$ ). This secondary storm track, located in the central LDA, is likely driven by $\mathrm{PF}$ trough intrusions into that region (rather than intrusions into the western LDA), where large ring formation and deep cyclogenesis has been observed by Chereskin et al. (2009). In composite-mean fields during a subset of eddy events in the western LDA, the secondary peak in $\mathbf{W}^{z}$ is greatly reduced in magnitude relative to the primary peak (Fig. 6a). This supports the hypothesis that the secondary storm track is generated by PF trough intrusions locally into the central LDA rather than being an extension of the primary western storm track.

The divergence of $\mathbf{W}^{H}$ out of the western $\psi$ anomaly seen in Fig. 8 on 23 July suggests the mean flow taking wave activity back from the eddies (assuming no localized diabatic forcing and nonlinear effects). An idealized modeling study showing a time-mean ACC-like storm track found this process, indicative of upgradient fluxes, to occur farther downstream of the ridge (Youngs et al. 2017). The divergence of $\mathbf{W}^{H}$, and thus suggestion of the mean flow gaining energy from the eddies, occurs here immediately in the lee of the SFZ, several days after the major mean-to-eddy conversion of wave activity (Fig. 8, bottom row). Diagnosing $\mathbf{W}$ in a high-resolution ocean model could help to elucidate the time-dependent dynamics, that are sure to be more complicated than those seen in a time-mean sense.

Cyclonic (clockwise) horizontal $\overline{\mathbf{W}^{H}}$ vectors in the eastern LDA in Fig. 2 may be associated with large ring formation events, such as that documented by Chereskin et al. (2009), yet the nonlinearity of rings breaks the assumptions made in the formulation of $\mathbf{W}$. However, the $\overline{\mathbf{W}^{H}}$ vectors in the northeast corner of the LDA appear to circulate around the mean ring (closed SSH contour) in Fig. 2. Alternatively, the cyclonic horizontal fluxes could be associated with the deep circulation found by Ferrari et al. (2012) in the Yaghan basin, a deep basin in northern Drake Passage centered near $56^{\circ} \mathrm{S}$, $61^{\circ} \mathrm{W}$. Further work is necessary to understand the rotational aspects of $\overline{\mathbf{W}^{H}}$ and elucidate the dynamics in this region, where information from outside the observational CPIES array is required.

\section{b. Physical mechanisms of a storm track}

One advantage of a wave activity flux framework is that each set of terms in $\mathbf{W}, \mathbf{W}_{\text {eddy }}$ and $\mathbf{W}_{\text {ageo }}$, is associated with specific physical processes (section 2). The complementary phase-dependent terms combine together to form a phase-independent flux, making the interpretation of $\mathbf{W}$ consistent throughout the entire storm track. Additionally, considering each set of terms individually allows for their relative contributions to the storm track dynamics to be determined. That is, the relative influence of eddy-driven fluxes $\mathbf{W}_{\text {eddy }}$ [Eq. (3)] and ageostrophically induced fluxes $\mathbf{W}_{\text {ageo }}$ [Eq. (4)] on the storm track dynamics can be quantified. Figure 7 shows the composite-mean $\mathbf{W}^{z}$ is split roughly evenly between eddy and ageostrophic fluxes, while the ageostrophic fluxes dominate $\mathbf{W}^{H}$. While much focus is often paid to eddy fluxes (e.g., Watts et al. 2016; Phillips and Rintoul 2000), Firing et al. (2016) note that the ageostrophic gradient wind flow is crucial for calculating the vorticity budget in Drake Passage, particularly for the vortex-stretching term.

Another advantage of diagnosing $\mathbf{W}$ is that both eddy energy and enstrophy are inherently included in the analysis. Since $\mathbf{W}$ transports wave activity, it transports a combination of eddy energy and enstrophy together. In this way, eddy energy and enstrophy are entangled in the analysis, and cannot be diagnosed individually. However, since the scaled eddy energy term is much greater than the scaled eddy enstrophy term $(\bar{E}>\bar{A} ;$ Fig. 3), an energetics viewpoint is discussed here. Yet, it can be noted that the eddy enstrophy field in Fig. 3d broadly mirrors the $\overline{\mathrm{EPE}}$ field in Fig. 4a, not a surprising result given that quasigeostrophic potential vorticity of the mean PF is dominated by the thickness or buoyancy term in Drake Passage (Foppert et al. 2016).

There are two instability processes for energy to transfer from the mean flow to eddies: the baroclinic and the barotropic pathways. The baroclinic pathway initially converts APE to EPE through a horizontal eddy buoyancy flux, or an equivalent downward eddy momentum flux. This process is clearly at play here, as evidenced by the collocation of enhanced $\mathbf{W}^{z}$ (Fig. 2) and enhanced divergent EHF (Watts et al. 2016). To complete the baroclinic pathway to EKE, conversion from EPE to EKE occurs through vertical eddy buoyancy fluxes. Alternatively, eddies can gain energy through the barotropic pathway, converting mean 
kinetic energy directly to EKE. The consistent alignment of the EKE maximum with $\mathbf{W}^{H}$ convergence suggests the barotropic pathway is nonnegligible, and perhaps even stronger than the baroclinic pathway for EKE production (Figs. 5, 6g,j). Further, during the event presented in Fig. 8, the largest values of EKE on 17 July are found prior to the strongest $\mathbf{W}^{z}$ and prior to the strongest EPE and $\mathbf{W}^{z}$, as well as prior to the strongest horizontal EHF found in Watts et al. (2016). This also implies the barotropic pathway of energy from the mean flow to eddies in this oceanic storm track.

The physical mechanisms responsible for the dynamics of the oceanic storm track in Drake Passage are illustrated schematically in Fig. 9. Following linear instability theory, it begins with a small perturbation to a mean ACC jet. If, by circumstance, the configuration of the upper and deep pressure fields is such that the deep anomaly offsets the upper anomaly by roughly a quarter wavelength, the two strengthen simultaneously. The strengthening of the anomalies and growth of the meander, that is, growth of the perturbation, is associated with a horizontal EHF (vertical eddy momentum flux), baroclinic instability, and EPE production. As the meander grows and increases its curvature, the sub- (super-) geostrophic flow in the trough (crest) intensifies and there is an increase in $\mathbf{W}_{\text {ageo }}$. By changing the horizontal distribution of PV around the jet core, increased horizontal velocity shear associated with the meander growth also allows for horizontal eddy momentum flux, barotropic instability, and EKE production. In the atmosphere, where the flow does not have as complex bathymetry to navigate as the ACC does in Drake Passage, it appears that the EKE could subsequently provide energy to grow the adjacent downstream eddy. However, the work presented here suggests the downstream baroclinic development process of this oceanic storm track is truncated in Drake Passage. Moreover, the relative magnitude of EKE produced through the baroclinic pathway compared to barotropic pathway remains unknown, yet it is clear from this work that the barotropic pathway is nonnegligible.

While the physical processes driving the storm track's dynamics are described above in several steps, they appear to happen all, or nearly all, together. In particular, there is a strong correlation $\left(R^{2}=0.6\right)$ between horizontal and vertical $\mathbf{W}$ time series, averaged in the western LDA (west of $64^{\circ} \mathrm{W}$ ), when $\mathbf{W}^{H}$ lags $\mathbf{W}^{z}$ by 0.5 days. Similarly, but with weaker correlation coefficients, the regional-mean $\mathbf{W}_{\text {eddy }}$ components are most correlated when the horizontal terms lag the vertical terms by 0.5 days, while the horizontal and vertical terms of $\mathbf{W}_{\text {ageo }}$ are most correlated at zero lag. Horizontal eddy and ageostrophic flux terms are strongly correlated $\left(R^{2}=0.88\right)$ at zero lag, indicating the barotropic eddy and ageostrophic fluxes occur together. The interpretation of these lags is that the dynamics of the storm track are all intimately linked. That is, only half a day after the joint intensification of the upper and deep pressure anomalies where baroclinic instability drives the initial meander growth, the shear has increased enough to initiate barotropic instability through horizontal eddy momentum fluxes and the curvature has increased enough to generate strong ageostrophic fluxes of wave activity.

There is much interest in how the ACC equilibrates to changes in wind forcing. Thompson and Naveira Garabato (2014) suggest, through vorticity dynamics in an eddy-resolving global circulation model, a rapid barotropic response to wind stress changes, where changes to the barotropic vorticity balance manifest as changes in meander characteristics. These changes to the meander's curvature and/or wavelength have implications for $\mathbf{W}$. For example, an increase in meander curvature will increase the ageostrophic gradient wind flow and, thus, increase the ageostrophic flux terms of W. Thompson and Naveira Garabato (2014) also show that increases in curvature are associated with increases in EKE. The increased curvature increases the horizontal velocity shear, thus making the front more susceptible to barotropic instability and further opens the barotropic pathway to EKE directly from the mean flow.

\section{Conclusions}

In this study, observation-based wave activity $M$ and its flux $\mathbf{W}$ and eddy energy (EKE and EPE) are presented in the eddy-rich interfrontal zone between the SAF and PF downstream of the Shackleton Fracture Zone in Drake Passage. These quantities are calculated from direct observations made by CPIES during the 4 years of the cDrake experiment, from November 2007 through November 2011, and averaged in the upper to midwater column (400-100-m depth). Presented in three ways-4-yr time mean, composite-mean of eddy events that make up about $15 \%$ of the 4 -yr time series, and a case study of an eddy event during which a PF trough intrudes into the western LDA - the dynamics of the oceanic storm track are consistently tied to both the horizontal and vertical components of $\mathbf{W}$. The horizontal and vertical fluxes highlight the importance of barotropic and baroclinic processes, respectively, in transferring $M$ through an oceanic storm track. Further, the total eddy energy dominates over eddy enstrophy in terms of wave activity; that is, $\bar{E}$ is more than an order of magnitude larger than $\bar{A}$ in the main storm track (Fig. 3), 


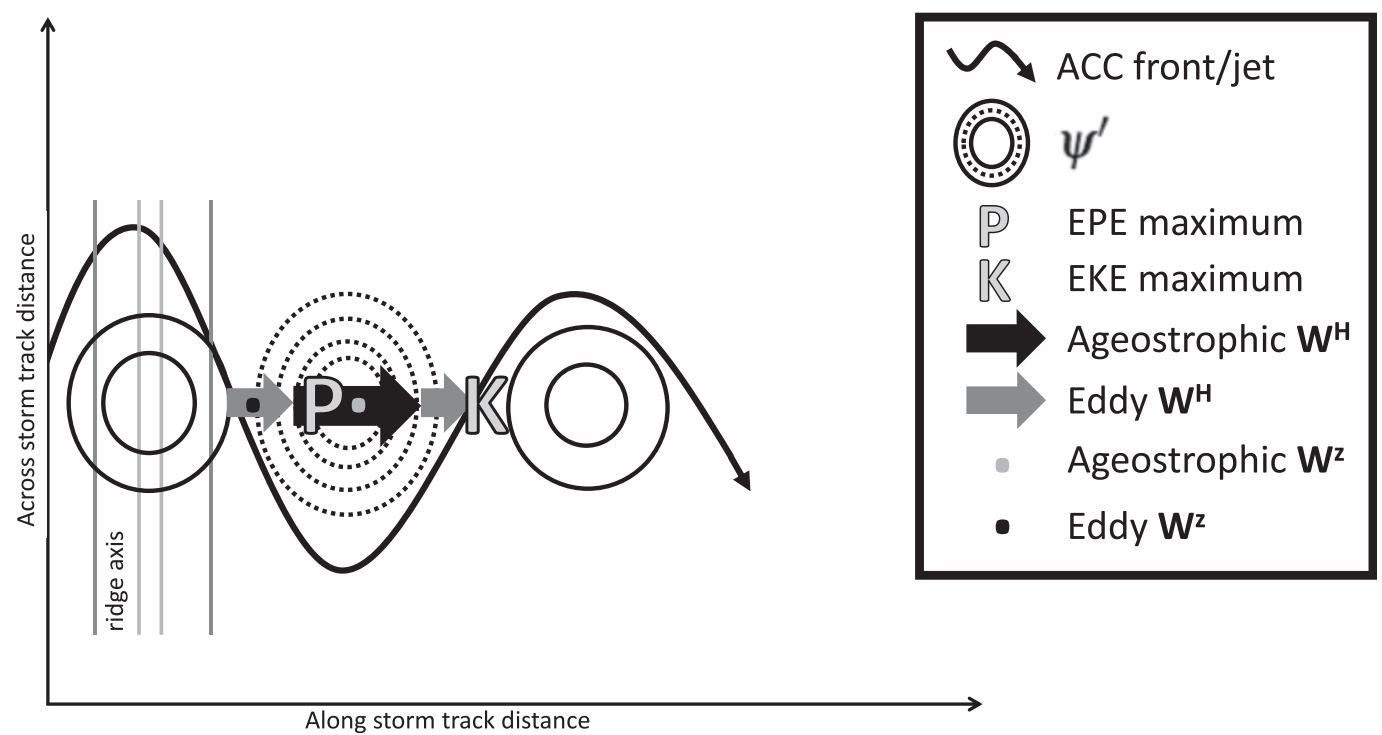

FIG. 9. Simplified illustration of the dynamics and physical mechanisms for an oceanic storm track. The arrows represent $\mathbf{W}^{H}$, and dots represent $\mathbf{W}^{z}$, with the strength of the fluxes indicated by the size of the symbols; solid and dashed contours represent geostrophic streamfunction anomalies; curved line represents an ACC front; gray lines represent the ridge axis; and uppercase $\mathrm{P}$ and $\mathrm{K}$ represent eddy potential and kinetic energy maxima, respectively. The strengthening of the anomalies and growth of the initial perturbation due to the configuration of the upper and deep pressure anomalies generates a horizontal eddy heat flux, baroclinic instability, and EPE production (upstream-most gray arrow and uppercase P). As the meander grows and increases its curvature, the sub- (super-) geostrophic flow in the trough (crest) intensifies, and there is an increase in the ageostrophic component of $\mathbf{W}$ (middle black arrow). By changing the horizontal distribution of PV around the jet core, increased horizontal velocity shear associated with the meander growth also allows for horizontal eddy momentum flux, barotropic instability, and EKE production (uppercase K).

leading to an eddy energetics perspective of the observed dynamics.

The main storm track in the Drake Passage array of CPIES is in the western part of the LDA, immediately downstream of the SFZ, where a standing meander (SAF crest) can be seen in the satellite SSH data (Figs. 1, 2). Horizontal and vertical components of wave activity flux $\mathbf{W}$ are elevated in this region, with heightened values in a composite-mean of eddy events and during both PF trough and SAF crest intrusions (Fig. 6). In general, $\mathbf{W}^{H}$ vectors point across $\psi^{\prime}$ contours toward the region of elevated EKE (Figs. 5, 6). That is, increased wave activity immediately downstream of the SFZ is transported out of the region by $\mathbf{W}^{H}$ and feeds the adjacent elevated EKE values. While Watts et al. (2016) clearly document baroclinic growth and instability in this region, this work illustrates the additional influence of barotropic instability that had yet to be observed.

This work illustrates the role of $\mathbf{W}^{H}$ in setting the downstream offset of EKE and maintaining the structure of eddy energetics in the oceanic storm track. This indicates the importance of barotropic processes and suggests the presence of mixed barotropic-baroclinic instability. Finally, in order to properly parameterize global circulation and climate models to accurately simulate the transfers of energy and enstrophy, that is, wave activity, through the ACC system, all the processes responsible for those transfers must first be understood. The observed importance of barotropic processes in this work presents a challenge to the modeling community. The wave activity flux framework presented here will help identify and quantify the relative importance of physical mechanisms controlling transfers of energy and enstrophy between eddies and the mean flow in the ocean. A future study analyzing a high-resolution ocean model with realistic bathymetry will be especially useful.

Acknowledgments. This work was supported by the National Science Foundation Grant OCE1141802 and the Centre for Southern Hemisphere Oceans Research (CSHOR), a collaborative research partnership between Qingdao National Laboratory for Marine Science and Technology (QNLM) and CSIRO, along with CSHOR's partners University of Tasmania and University of New South Wales. cDrake data are available 
at the National Centers for Environmental Information, online at http://www.nodc.noaa.gov. Many thanks to Kathy Donohue, Randy Watts, and Karen Tracey for the helpful discussions and guidance throughout this work; thanks also to Steve Rintoul for constructive comments and feedback on the manuscript. Comments from two anonymous reviewers that helped to significantly improve this work are much appreciated.

\section{REFERENCES}

Bischoff, T., and A. F. Thompson, 2014: Configuration of a Southern Ocean storm track. J. Phys. Oceanogr., 44, 30723078, https://doi.org/10.1175/JPO-D-14-0062.1.

Bishop, S. P., D. R. Watts, and K. A. Donohue, 2013: Divergent eddy heat fluxes in the Kuroshio Extension at $144^{\circ}-146^{\circ}$ E. Part I: Mean structure. J. Phys. Oceanogr., 43, 1533-1550, https:// doi.org/10.1175/JPO-D-12-0221.1.

Chapman, C. C., A. M. Hogg, A. E. Kiss, and S. R. Rintoul, 2015: The dynamics of Southern Ocean storm tracks. J. Phys. Oceanogr., 45, 884-903, https://doi.org/10.1175/JPO-D-14-0075.1.

Chereskin, T. K., K. A. Donohue, D. R. Watts, K. L. Tracey, Y. L. Firing, and A. L. Cutting, 2009: Strong bottom current and cyclogenesis in Drake Passage. Geophys. Res. Lett., 36, L23602, https://doi.org/10.1029/2009GL040940.

,$- \ldots$, and -2012 : cDrake: Dynamics and transport of the Antarctic Circumpolar Current in Drake Passage. Oceanography, 25, 134-135, https://doi.org/10.5670/oceanog.2012.86.

Chidichimo, M. P., K. A. Donohue, D. R. Watts, and K. L. Tracey, 2014: Baroclinic transport time series of the Antarctic Circumpolar Current measured in Drake Passage. J. Phys. Oceanogr., 44, 1829-1853, https://doi.org/10.1175/ JPO-D-13-071.1.

Cronin, M., 1996: Eddy-mean flow interaction in the Gulf Stream at $68^{\circ} \mathrm{W}$. Part II: Eddy forcing on the time-mean flow. J. Phys. Oceanogr., 26, 2132-2151, https://doi.org/ 10.1175/1520-0485(1996)026<2132:EMFIIT >2.0.CO;2.

Danielson, R. E., J. R. Gyamkun, and D. N. Straub, 2006: A case study of downstream baroclinic development over the North Pacific Ocean. Part II: Diagnoses of eddy energy and wave activity. Mon. Wea. Rev., 134, 1549-1567, https://doi.org/ 10.1175/MWR3173.1

Eliassen, A., and E. Palm, 1961: On the transfer of energy in stationary mountain waves. Geofys. Publ., 22, 1-23.

Ferrari, R., C. Provost, A. Renault, N. Sennéchael, N. Barré, Y.-H. Park, and J. H. Lee, 2012: Circulation in Drake Passage revisited using new current time series and satellite altimetry: 1. The Yaghan Basin. J. Geophys. Res. Oceans, 117, C12024, https://doi.org/10.1029/2012JC008264.

Firing, Y. L., T. K. Chereskin, D. R. Watts, K. L. Tracey, and C. Provost, 2014: Computation of geostrophic streamfunction, its derivatives, and error estimates from an array of CPIES in Drake Passage. J. Atmos. Oceanic Technol., 31, 656-680, https://doi.org/10.1175/JTECH-D-13-00142.1.

,,,--- and M. R. Mazloff, 2016: Bottom pressure torque and the vorticity balance in Drake Passage. J. Geophys. Res. Oceans, 121, 4282-4302, https://doi.org/10.1002/2016JC011682.

Foppert, A., K. A. Donohue, and D. R. Watts, 2016: The Polar Front in Drake Passage: A composite-mean stream-coordinate view. J. Geophys. Res. Oceans, 121, 1771-1788, https://doi.org/10.1002/ 2015JC011333. ,,$---\longrightarrow$, and K. L. Tracey, 2017: Eddy heat flux across the Antarctic Circumpolar Current estimated from sea-surface height standard deviation. J. Geophys. Res. Oceans, 122, 6947-6964, https://doi.org/10.1002/2017JC012837.

Hoskins, B. J., and P. J. Valdes, 1990: On the existence of stormtracks. J. Atmos. Sci., 47, 1854-1864, https://doi.org/10.1175/ 1520-0469(1990)047<1854:OTEOST>2.0.CO;2.

Jackett, D. R., and T. J. McDougall, 1997: A neutral density variable for the world's oceans. J. Phys. Oceanogr., 27, 237-263, https:// doi.org/10.1175/1520-0485(1997)027<0237:ANDVFT>2.0.CO;2.

Kaspi, Y., and T. Schneider, 2011: Downstream self-destruction of storm tracks. J. Atmos. Sci., 68, 2459-2464, https://doi.org/ 10.1175/JAS-D-10-05002.1.

Klocker, A., R. Ferrari, and J. H. LaCasce, 2012: Estimating suppression of eddy mixing by mean flows. J. Phys. Oceanogr., 42, 1566-1576, https://doi.org/10.1175/JPO-D-11-0205.1.

Lorenz, E. N., 1955: Available potential energy and the maintenance of the general circulation. Tellus, 7, 157-167, https:// doi.org/10.3402/tellusa.v7i2.8796.

Nakamura, M., M. Kadota, and S. Yamane, 2010: Quasigeostrophic transient wave activity flux: Updated climatology and its role on polar vortex anomalies. J. Atmos. Sci., 67, 3164-3189, https://doi.org/10.1175/2010JAS3451.1.

Naveira Garabato, A. C., R. Ferrari, and K. L. Polzin, 2011: Eddy stirring in the Southern Ocean. J. Geophys. Res. Oceans, 116, C09019, https://doi.org/10.1029/2010JC006818.

Nikurashin, M., and G. Vallis, 2012: A theory of the interhemispheric meridional overturning circulation and associated stratification. J. Phys. Oceanogr., 42, 1652-1667, https://doi.org/ 10.1175/JPO-D-11-0189.1.

Nowlin, W. D., Jr., S. J. Worley, and T. Whitworth III, 1985: Methods for making point estimates of eddy heat flux as applied to the Antarctic Circumpolar Current. J. Geophys. Res., 90, 3305-3324, https://doi.org/10.1029/JC090iC02p03305.

Orlanski, I., and J. J. Katzfey, 1991: The life cycle of a cyclone wave in the Southern Hemisphere. Part I: Eddy energy budget. J. Atmos. Sci., 48, 1972-1998, https://doi.org/10.1175/ 1520-0469(1991)048<1972:TLCOAC $>2.0$. CO;2.

—, and J. P. Sheldon, 1993: A case of downstream baroclinic development over western North America. Mon. Wea. Rev., 121, 2929-2950, https://doi.org/10.1175/1520-0493(1993)121<2929: ACODBD $>2.0 . \mathrm{CO} ; 2$.

$\longrightarrow$, and - 1995: Stages in the energetics of baroclinic systems. Tellus, 47A, 605-628, https://doi.org/10.3402/tellusa.v47i5.11553.

Pedlosky, J., 1987: Geophysical Fluid Dynamics. 2nd ed., Springer, $710 \mathrm{pp}$.

Phillips, H. E., and S. R. Rintoul, 2000: Eddy variability and energetics from direct current measurements in the Antarctic Circumpolar Current south of Australia. J. Phys. Oceanogr., 30, 3050-3076, https://doi.org/10.1175/1520-0485(2000)030<3050: EVAEFD $>2.0 . \mathrm{CO} ; 2$

Plumb, R. A., 1983: A new look at the energy cycle. J. Atmos. Sci., 40, 1669-1688, https://doi.org/10.1175/1520-0469(1983)040<1669: ANLATE $>2.0 . \mathrm{CO} ; 2$.

_ 1985: On the three-dimensional propagation of stationary waves. J. Atmos. Sci., 42, 217-229, https://doi.org/10.1175/ 1520-0469(1985)042<0217:OTTDPO >2.0.CO;2.

Rintoul, S. R., 2018: The global influence of localized dynamics in the Southern Ocean. Nature, 558, 209-218, https://doi.org/ 10.1038/s41586-018-0182-3.

Smith, K. S., and J. Marshall, 2009: Evidence for enhanced eddy mixing at middepth in the Southern Ocean. J. Phys. Oceanogr., 39, 50-69, https://doi.org/10.1175/2008JPO3880.1. 
Takaya, K., and H. Nakamura, 1997: A formulation of a waveactivity flux for stationary Rossby waves on a zonally varying basic flow. Geophys. Res. Lett., 24, 2985-2988, https://doi.org/ 10.1029/97GL03094.

_ , and —, 2001: A formulation of a phase-independent wave-activity flux for stationary and migratory quasigeostrophic eddies on a zonally varying basic flow. J. Atmos. Sci., 58, 608-627, https://doi.org/10.1175/1520-0469(2001) $058<0608$ :AFOAPI $>2.0 . \mathrm{CO} ; 2$.

Thompson, A. F., and A. C. Naveira Garabato, 2014: Equilibration of the Antarctic Circumpolar Current by standing meanders. J. Phys. Oceanogr., 44, 1811-1828, https://doi.org/10.1175/ JPO-D-13-0163.1.

-, and J.-B. Sallée, 2012: Jets and topography: Jet transitions and the impact on transport in the Antarctic Circumpolar Current. J. Phys. Oceanogr., 42, 956-972, https://doi.org/ 10.1175/JPO-D-11-0135.1.

Toggweiler, J. R., and B. Samuels, 1995: Effect of Drake Passage of the global thermohaline circulation. Deep-Sea Res. I, 42, 477-500, https://doi.org/10.1016/0967-0637(95)00012-U.
Tracey, K. L., K. A. Donohue, D. R. Watts, and T. K. Chereskin, 2013: cDrake CPIES data report November 2007 to December 2011. GSO Tech. Rep. 2013-01, University of Rhode Island Physical Oceanography, 72 pp., https://digitalcommons.uri. edu/physical_oceanography_techrpts/4/.

Watts, D. R., K. L. Tracey, K. A. Donohue, and T. K. Chereskin, 2016: Estimates of eddy heat flux crossing the Antarctic Circumpolar Current from observations in Drake Passage. J. Phys. Oceanogr., 46, 2103-2122, https://doi.org/10.1175/JPO-D-16-0029.1.

Williams, R. G., C. Wilson, and C. W. Hughes, 2007: Ocean and atmosphere storm tracks: The role of eddy vorticity forcing. J. Phys. Oceanogr., 37 (9), 2267-2289, https://doi.org/10.1175/JPO3120.1.

Wolf, G., and V. Wirth, 2017: Diagnosing the horizontal propagation of Rossby wave packets along the midlatitude waveguide. Mon. Wea. Rev., 145, 3247-3264, https://doi.org/ 10.1175/MWR-D-16-0355.1.

Youngs, M. K., A. F. Thompson, A. Lazar, and K. J. Richards, 2017: ACC meanders, energy transfer, and mixed barotropicbaroclinic instability. J. Phys. Oceanogr., 47, 1291-1305, https:// doi.org/10.1175/JPO-D-16-0160.1. 